\title{
Organic waste recycling in agriculture and related effects on soil water retention and plant available water: a review
}

\author{
Marie Eden ${ }^{1,2}$ (D) Horst H. Gerke ${ }^{3} \cdot$ Sabine Houot $^{2}$
}

Accepted: 21 February 2017 /Published online: 24 March 2017

(C) INRA and Springer-Verlag France 2017

\begin{abstract}
The decrease of organic matter content in agricultural soils is a problem of great concern to farmers around the world. Indeed, it lowers soil fertility that directly impairs agricultural crop production and affects a number of other soil properties like water retention capacity, aggregation and structure formation, soil mechanical strength or compactibility. Scarcity in plant available water poses a risk to agriculture, especially in drought-prone areas. However, the increase of organic waste recycling in agriculture may also lead to an increase in soil organic matter contents and to changes in related soil properties. Here, we review 17 long-term field experiments ( $\geq 9$ years) that investigated the effects of organic amendments on organic carbon and water availability in topsoils. We paid particular attention to the effects of added organic matter on soil bulk density or porosity and consequently on plant available water. Our main findings are that (1) plant available water generally improves after organic waste addition (relative changes from -10 to $+30 \mathrm{vol} \% ; p=0.052$ ), (2) organic matter quality affects changes in organic carbon $(p<0.05)$, (3) it is more suitable for plant available water quantification to use volumetric rather than gravimetric water contents, (4) the value of the matric potential defining field capacity is an issue, (5) pedotransfer functions developed for American soils adequately predicted most water contents at field capacity and wilting point, and (6) prevailing climate and initial organic
\end{abstract}

Marie Eden

mariemeden@gmail.com

1 Technical University of Munich, Geomorphology and Soil Science, Freising-Weihenstephan, Germany

2 UMR ECOSYS, INRA, AgroParisTech, Université Paris-Saclay, 78850 Thiverval-Grignon, France

3 Leibniz-Centre for Agricultural Landscape Research (ZALF), Soil Landscape Research, Müncheberg, Germany carbon content may affect plant available water. This review confirms that organic amendments generally induce beneficial effects on plant available water and other soil properties. It also highlights the influence of organic matter quality on soil organic carbon. Compared with a previous review, this study reinforces reported trends of increasing plant available water with organic waste additions. This may be due to a more restrictive selection of recently published data and the use of volumetric water contents. Our findings are significant for sustainable agriculture regarding the sustainable use of organic wastes and water.

Keywords Long-term experiment - Organic amendment . Organic carbon $\cdot$ Water retention $\cdot$ Plant available water capacity $\cdot$ Indicator of residual organic carbon
Abbreviations
OC Organic carbon
OM Organic matter
FC Field capacity
WP Wilting point
PAW Plant available water

\section{Contents}

1. Introduction

1.1 Field capacity and wilting point

1.2 Plant available water

2. Purpose of the review and available database

3. Impact of organic wastes

3.1 Soil OC content and bulk density

3.2 Volumetric versus gravimetric water content

3.3 Water holding capacity

3.3.1 Water retention at FC and WP

3.3.2 Water retention between FC and WP 


\subsection{Predicting soil water retention}

3.4.1 Impact of texture and carbon content

3.4.2 Impact of organic waste addition

3.5 Impact of climate

4. Summary and conclusions

Acknowledgements

References

\section{Introduction}

The use of organic wastes in agriculture provides the opportunity to simultaneously increase soil productivity and potentially offer a more sustainable way of dealing with organic wastes. From the agricultural productivity point of view, the problem was exemplary formulated by Amundson et al. (2015): "Given little opportunity or desirability for further agricultural expansion, stewardship of our existing domesticated soil is essential for sustained human prosperity". Many recent studies highlight the importance of soil organic matter (OM) with regard to climate change (Adewopo et al. 2014; Amundson et al. 2015; Baveye 2015; Lin 2014). Moreover, among the grand challenges in research on soil processes, also the need for modified agricultural practices in order to improve water and nutrient retention of the cropped soil layer was expressed by Baveye (2015). According to Sposito (2013), an increase in available green water (i.e. soil water directly available to plant roots) is even more so important, since the increase in agricultural food production will have to be met by increased yields per area and not via land use change. However, according to climate change predictions, some areas are likely to encounter decreased precipitation and increased temperatures as stated by the Intergovernmental Panel on Climate Change (IPCC 2007), while water availability for irrigation is likely to decrease due to overall higher demand (Monaco et al. 2014; Bouma et al. 2015).

Organic wastes from various sources have traditionally been and are currently being used as amendments in agriculture (Khaleel et al. 1981). Manures and plant residues have been traditionally incorporated into the soil (e.g. Fig. 1) to maintain soil organic carbon (OC) levels and improve soil properties that are affected by $\mathrm{OC}$ contents. Other organic materials, like processing wastes, municipal solid waste, green wastes or sewage sludge, can also be turned into valuable resources, e.g. by composting and subsequent application to agricultural soil (e.g. Diacono and Montemurro 2010). At the same time, this practice satisfies the demand for waste recycling (Amundson et al. 2015), consequently reducing the amount of waste being incinerated or deposited in landfills (Diacono and Montemurro 2010). Moreover, organic wastes contain various nutrients, which can reduce the need for mineral fertilizers, which is particularly important in regard to declining mineral fertilizer resources e.g. of phosphorus (Adewopo et al. 2014; Amundson et al. 2015).

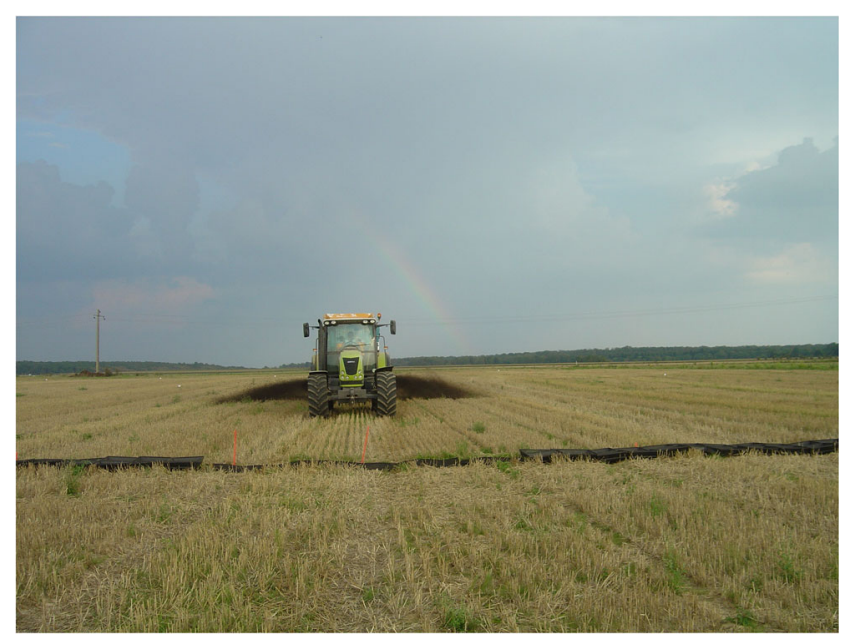

Fig. 1 Spreading of biocompost in the long-term experiment Qualiagro in Feucherolles, France. The experiment was established in 1998 on silt loam soil; four organic wastes are applied every other year in fall. For location, see Fig. 3; for more details, see Table 1 (photo by Sabine Houot)

Quantity and quality of the applied exogenous OM (i.e. OM applied with the amendments) affect soil properties (Diacono and Montemurro 2010) and hence need to be considered, when planning field applications. Manure additions for up to more than 100 years increased soil OC in a silty clay loam in Rothamsted, the oldest agricultural long-term experiment of the world (Johnston 1986); similar observations were reported in a review on a variety of experiments (Haynes and Naidu 1998). Also, shorter-term studies mention this positive effect on soil OC, like a 15-year experiment in Davis, CA, with compost additions (Eden et al. 2012a) or a 7-year study in Sao Paulo, Brazil, with sewage sludge applications (Bueno et al. 2011). Khaleel et al. (1981) reported a significant reduction in soil bulk density at increasing soil OC contents for different amendments, application rates and soil types. Their findings regarding bulk density were corroborated by Anderson et al. (1990) on a 100-year experiment with annual manure additions at a rate of $13.5 \mathrm{t} / \mathrm{ha}$. Several recent studies found that total water holding capacity or total porosity was larger in long-term organically amended soils than in unamended soils (Bastida et al. 2007; Rasool et al. 2008; Riley et al. 2008; Zhao et al. 2009). Also, Khaleel et al. (1981) cited numerous studies that found an increase in the water holding capacity with increasing soil OC content following long-term organic waste applications.

Tittarelli et al. (2007) summarized the ideal characteristics of organic amendments like compost mentioning also a high degree of OM stability, which they regard as a key issue of compost quality. Haynes and Naidu (1998) highlighted the importance of exogenous OM quality in their review, and soil OC increased more with additions of composted than fresh materials. Also, the composition (i.e. quality) of the soil OM was found to be affected by long-term farmyard manure application since 1878 for the experiment in Halle (Kaiser et al. 
2007). Cass and McGrath (2005) discussed the importance of compost quality, possible risks and benefits related to its application and stated that the effectiveness of OM quantity on structural stability was short-lived. However, a study on silty soil found that addition of urban composts and manure for 9 years improved aggregate stability (Annabi et al. 2011). Abiven et al. (2009) reviewed the effects of organic inputs on aggregate stability, validating an older model (Monnier 1965) by confirming that easily decomposable products have an intense and transient effect while more recalcitrant products have a lower but longer-term effect. Aggregate stability is a key factor of soil physical fertility and soil structure (Diacono and Montemurro 2010) and thus of pore structure, which affects soil water retention. Moreover, soil water retention is influenced by OM quality in terms of its wettability and its ability to retain water (Ojeda et al. 2015). However, two recent studies (Ajayi et al. 2016; Liyanage and Leelamanie 2016) adding hydrophobic organic amendments to soil under laboratory conditions both found increases in plant available water, which was ascribed to improved stabilization of aggregates allowing for better water retention (Liyanage and Leelamanie 2016).

The concept of plant available water (PAW) was described as early as 1927 in Davis, CA, when Veihmeyer and Hendrickson (1927) found out that some $48 \mathrm{~h}$ after irrigation, further downward movement of water became negligibly small and soil water content approached field capacity (FC) and that the water uptake of trees was not affected until wilting point (WP) was reached. However, according to Hudson (1994) for several decades to come and in spite of contradictory findings, OM was often incorrectly assumed to have no impact on PAW, as increases at FC were presumably counterbalanced by those at WP, or PAW increases were discounted as exceptions to the rule. Olness and Archer (2005) stated that Hudson (1994) "was really the first to illustrate the complexity of the effect of OC on soil water retention" estimating increases in available soil water between 2.2 and $3.7 \%$ for every unit percent increase in OC. More details on the theory of available water capacity and its historical development can be found in Minasny and McBratney (2003). PAW was found to increase in organically amended soils in recent short-term ( $<9$ years) (Foley and Cooperband 2002; Ozenc and Ozenc 2008) and long-term (>9 years) (Shukla et al. 2004; Zhao et al. 2009) studies; however, also, reductions in PAW were observed (Herencia et al. 2011). Differences in the increase of PAW have been observed as a result of the type of amendment (i.e. manure vs. plant residues) (Olness and Archer 2005).

Even though many articles focus on the influence of organic wastes on soil, only few of them are based on long-term studies. The duration of field experiments is essential as only longer-term studies can capture all the complex effects of OC on e.g. soil structure, which may evolve slowly, over years
(Diacono and Montemurro 2010). In this respect, long-term experiments are essential as their results can be used to better understand how to maintain and increase crop production while maintaining soil quality (Körschens 2006). Such field experiments are particularly appropriate for the analyses of long-term dynamics of soil water retention (Huntington 2006) and other soil properties.

The focus of this paper was to review and analyse the impact of the application of organic wastes in agriculture on water retention between FC and WP, which determines the amount of soil water available for plants in the topsoil, where amendments are incorporated. Results from 17 field experiments are used for comparisons regarding the impact of organic waste application. In this context, PAW is related to the change in soil OC content, which is used as a key parameter, reflecting the direct impact of organic waste applications. Moreover, PAW greatly depends on the choice of matric potential for FC; this also presents an issue. The review includes recently published data from long-term field experiments with organic waste applications and unamended control plots that were continuing for a period of at least 9 years.

The novelty of this review, especially compared to that by Khaleel et al. (1981), comprises several aspects: (i) it is based on recently published data, (ii) it considers not only quantity but also quality of exogenous OM applied, (iii) it is based on volumetric instead of gravimetric water content, and (vi) it applies pedotransfer functions to predict the water contents of interest. As such, this review addresses UN Sustainable Development Goals 2 (End hunger, achieve food security and improved nutrition and promote sustainable agriculture), 6 (Ensure availability and sustainable management of water and sanitation for all), 12 (Ensure sustainable consumption and production patterns), 13 (Take urgent action to combat climate change and its impacts) and 15 (Protect, restore and promote sustainable use of terrestrial ecosystems, sustainably manage forests, combat desertification, and halt and reverse land degradation and halt biodiversity loss) (UN 2014).

\subsection{Field capacity and wilting point}

Soil water retention and PAW (also called available water capacity) are largely dependent on soil structure (or poresize distribution), texture (or particle-size distribution), bulk density and OC content (Pollacco 2008; Wosten et al. 2001). Rawls et al. (2003) proposed pedotransfer functions (PTFs) based on data from North American soils, accounting for the effect of texture and $\mathrm{OC}$ at two points: $\mathrm{FC}$ at a matric potential of $-33 \mathrm{kPa}(\sim \mathrm{pF} 2.5)$ and $\mathrm{WP}$ at $-1500 \mathrm{kPa}(\sim \mathrm{pF} 4.2)$. The results of these PTFs were found to be transferable (location) and satisfactory for prediction of FC and WP of Swedish soils (Katterer et al. 2006). FC characterizes a soil moisture status with small water movement when all larger pores are drained, the matric potential depends on soil and pore structure in the 
range of $\mathrm{pF} 2$ to $\mathrm{pF} \sim 2.5$ (Brady and Weil 2008; Huntington 2006), and bulk density is also relevant (Bruand et al. 1996). At WP, the remaining soil moisture is assumed to be unavailable to plants; the difference between FC and WP is defined as PAW. Equivalent pore sizes (diameter, $d(\mu \mathrm{m})$ ) at the respective matric potentials, $\psi$, in $\mathrm{hPa}$ can be calculated with the capillary rise equation as stated in e.g. Eden et al. (2011):

$d \approx \frac{3000}{-\Psi}=\frac{3000}{10^{p F}}$

FC varies between soils depending on soil texture and structure, and in addition, FC can be affected by the groundwater table for soils near it; however, this was disregarded for the present studies. Al Majou et al. (2008) showed that in situ volumetric water content at FC approximated $-10 \mathrm{kPa}(\mathrm{pF}$ ) when comparing it to water content measurements at various matric potentials in the laboratory, but field conditions are not entirely replicated in the laboratory (e.g. Marshall 1959). Nonetheless, when determining the water retention curve or PAW specifically, a threshold value of $\mathrm{pF} 2.5$ for $\mathrm{FC}$ is more often reported than $\mathrm{pF} 2$ in studies on the impact of organic waste applications on soil physical properties (Khaleel et al. 1981).

\subsection{Plant available water}

The water retention capacity can be influenced e.g. by exogenous $\mathrm{OM}$ addition, which has multiple effects. The structureforming potential (aggregation) of OM can increase water retention at $\mathrm{FC}$ via formation of larger pores. OM has a low bulk density (Rawls 1983), which can reduce soil bulk density. Moreover, OM has a relatively large surface area (Khaleel et al. 1981), possibly retaining more water also at high suctions (close to WP). Whether OM is of hydrophilic or hydrophobic nature also affects soil water retention (Bachmann et al. 2006), an additional reason why in spite of increased OC contents, reductions in the actual water holding capacity may possibly occur in studies under field conditions. A review by Kay (1997) discussed the impact of OC on soil structure, pointing out that increasing OC leads to an increase in available water capacity. Cogger (2005) demonstrated that the full range between FC and WP may only be relevant in droughttolerant areas, while in other regions, only the water held at the wetter end of this range should be considered as plant available, e.g. up to $-200 \mathrm{kPa}$ ( $\mathrm{pF} 3.3$ ). A different concept, the least limiting water range (LLWR) (da Silva et al. 1994), suggests two options, one for the wet and the other for the dry range: $\mathrm{FC}$ or sufficient root aeration and WP or possible root penetration, whichever is smaller or greater, respectively.
Minasny and McBratney (2003) developed an integral energy concept as a measure of soil-water availability. It is calculated from the integral of the water retention curve of a given soil and provides information about the amount of energy and thus water availability. Mamo et al. (2000) stated that PAW may not be the best indicator of the positive effect of e.g. compost applications on plants' potential water uptake because it is a static measure. They suggested to use the leaf water potential instead, as it takes variability into account and makes it possible to consider other causes of improved crop water use after organic waste application (e.g. enhanced root growth, deeper root depth, larger input of root biomass). However, leaf water potential is a plant-based measure, which only works on cropped fields and that changes with climatic variations but does not indicate long-term soil changes through organic waste applications.

It is well known that not all PAW is readily available and that closer to WP water stress may occur in plants, as it becomes harder for roots to extract the water. Figure 2 illustrates the concept of PAW in the context of soil wetness. Despite the limitations from the crop and plant sciences' point of view, the PAW concept is useful for the purpose of comparing the longterm effects of organic waste applications on soil properties. Moreover, PAW was defined on a volume basis in a widely used handbook on soil physical methods (Romano and Santini 2012). PAW as analogously to Romano and Santini (2012)

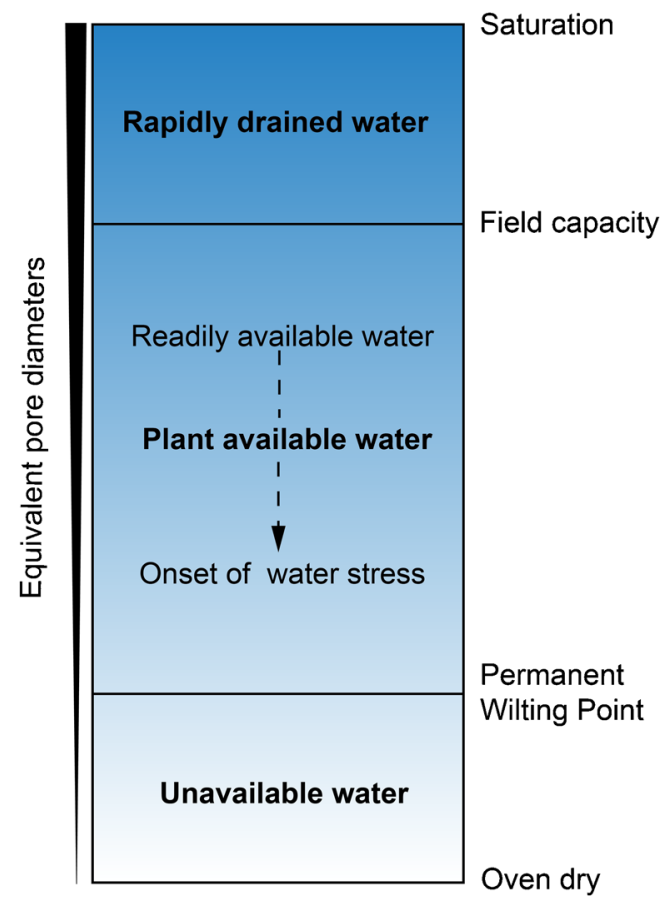

Fig. 2 Schematic of water-filled pore volume; with decreasing water content, more pores are air-filled; beginning with the largest pores (diameter), the relation of pore size and matric potential is given in Eq. 1 
defined in this paper is widely used and accepted, and water holding capacities at FC and WP are commonly measured; an available database on PAW values offers comparability between different locations as well as with older studies.

\section{Purpose of the review and available database}

The reviewed studies were investigating various types of organic wastes, focusing on their impact on soil water content in regard to sustainable agriculture. Only a limited number of relevant studies could be identified from title, abstract and

keyword search, which moreover fit the criteria outlined in the following.

The criteria for selection of studies were as follows:

- Application of organic waste and control treatment

- Duration of at least 9 years

- Necessary data reported in the study or provided by authors

per treatment:

- $\quad \mathrm{FC}$ (around $\mathrm{pF} 2.5$ ) and WP (around $\mathrm{pF} 4.2$ ) or PAW (between $\mathrm{pF} 2.5$ and 4.2) on a volumetric basis (if reported on gravimetric basis then multiplied with bulk density to transform it (Eq. 3))

- Soil OC content in grams per kilogram or \% $\mathrm{OC}(\%)=10^{*} \mathrm{OC}(\mathrm{g} / \mathrm{kg})$; if reported in tons per hectare, then transformed using $\mathrm{OC}(\%)=$ $\frac{\mathrm{OC}(\mathrm{t} / \mathrm{ha})}{\operatorname{depth}(\mathrm{m})^{*} \text { bulk density }\left(\mathrm{kg} / \mathrm{m}^{3}\right)}$ if reported as $\mathrm{OM}$, then transformed with $\mathrm{OC}=0.58^{*} \mathrm{OM}$ (e.g. Pribyl 2010) and bulk density

- Dry weight and application interval of the amendment

- Carbon content of the amendment (if reported in OM, then transformed using $\mathrm{OC}=\mathrm{OM} / 2$ (e.g. Brady and Weil 2008) in order to determine exogenous OC input and investigate its quality

- Texture for PTFs

- The individual studies reported data for different layer thicknesses; moreover, if a study stated a ploughing depth of e.g. $20 \mathrm{~cm}$, but data were reported e.g. for 0 10 and $10-20 \mathrm{~cm}$, then an average was calculated for $0-20 \mathrm{~cm}$.

Changes in FC, WP, soil OC and bulk density $\left(\rho_{\mathrm{b}}\right)$ are defined in relative $(\Delta \mathrm{FC}, \Delta \mathrm{WP}, \Delta \mathrm{OCr})$ and absolute $\left(\Delta \mathrm{OCa}, \Delta \rho_{\mathrm{b}}\right)$ terms:

- $\Delta \mathrm{FC}=\%$ change in water holding capacity at $\mathrm{FC}=$ [wasteincorporated soil FC - control soil FC]/(control soil FC) $* 100$

- $\Delta \mathrm{WP}=\%$ change in water holding capacity at WP
- $\Delta \mathrm{OCr}(\%)=\%$ change in soil $\mathrm{OC}$

- $\Delta \mathrm{OCa}(\mathrm{g} / \mathrm{kg})=[$ waste-incorporated soil OC - control soil OC]

- $\Delta \rho_{\mathrm{b}}=$ [waste-incorporated soil $\rho_{\mathrm{b}}-$ control soil $\rho_{\mathrm{b}}$ ]

Experimental sites differed concerning conditions and set-up, however, stressing longer-term research ( $\geq 9$ years); the oldest experiment (Bad Lauchstädt, Germany, Fig. 3) included in this review had been running for 106 years at the time of investigation. More studies reported data based on $\mathrm{FC}$ at $\mathrm{pF} \sim 2.5$, stating either PAW directly or FC and WP; therefore, this $\mathrm{pF}$ level was chosen. Most studies reported FC at -30 or $-33 \mathrm{kPa}(\mathrm{pF} 2.48$ and 2.52, respectively) and $\mathrm{WP}$ at $-1500 \mathrm{kPa}(\mathrm{pF} 4.18)$. The water holding capacity as the initial condition at the start of the experiment was rarely reported. Therefore, reference treatments in the form of (mineral fertilized) control treatments were used to show the benefits - if any - resulting from addition of organic amendments during the experiment. Hence, we compared the impact of mineral fertilizer application alone with that of organic amendments (plus mineral fertilizers where applicable).

In order to better understand the effects of exogenous OM addition on OC and PAW, these independent studies reported in literature were used. An overview over the locations is given in Fig. 3; more detailed information is provided in Table 1.

\section{Impact of organic wastes}

\subsection{Soil OC content and bulk density}

Exogenous OM additions have been reported to positively affect OC contents and bulk density, for short- as well as long-term studies. The indirect impact of exogenous OM addition on bulk density may in fact be more pronounced than directly related OC increases (Eden et al. 2012b). Figure 4a shows the absolute change of $\mathrm{OC}$ with respect to the input of exogenous OC applied with the organic amendments. Amounts of exogenous OC applied throughout the duration of the experiments range from $\sim 7$ to $227 \mathrm{t} / \mathrm{ha}$, while absolute changes in OC vary between 0.4 and $16.7 \mathrm{~g} / \mathrm{kg}$. There is a weak, but statistically significant relation between exogenous OC input and absolute change in $\mathrm{OC}$ in gram per kilogram $\left(p<0.05^{*}\right)$ as well as relative percent change in OC $\left(p<0.05^{*}\right)$. In another review on the impact of organic amendments on soil fertility (Diacono and Montemurro 2010), this positive effect on OC content was also highlighted. For bulk density, $\rho_{\mathrm{b}}$ (Fig. $4 \mathrm{~b}$ ), a strong statistically significant linear relationship $\left(p<0.001^{* * *}\right)$ between absolute change in OC and absolute change (decrease) in bulk density is observable. A decreasing bulk density with increasing OC content 


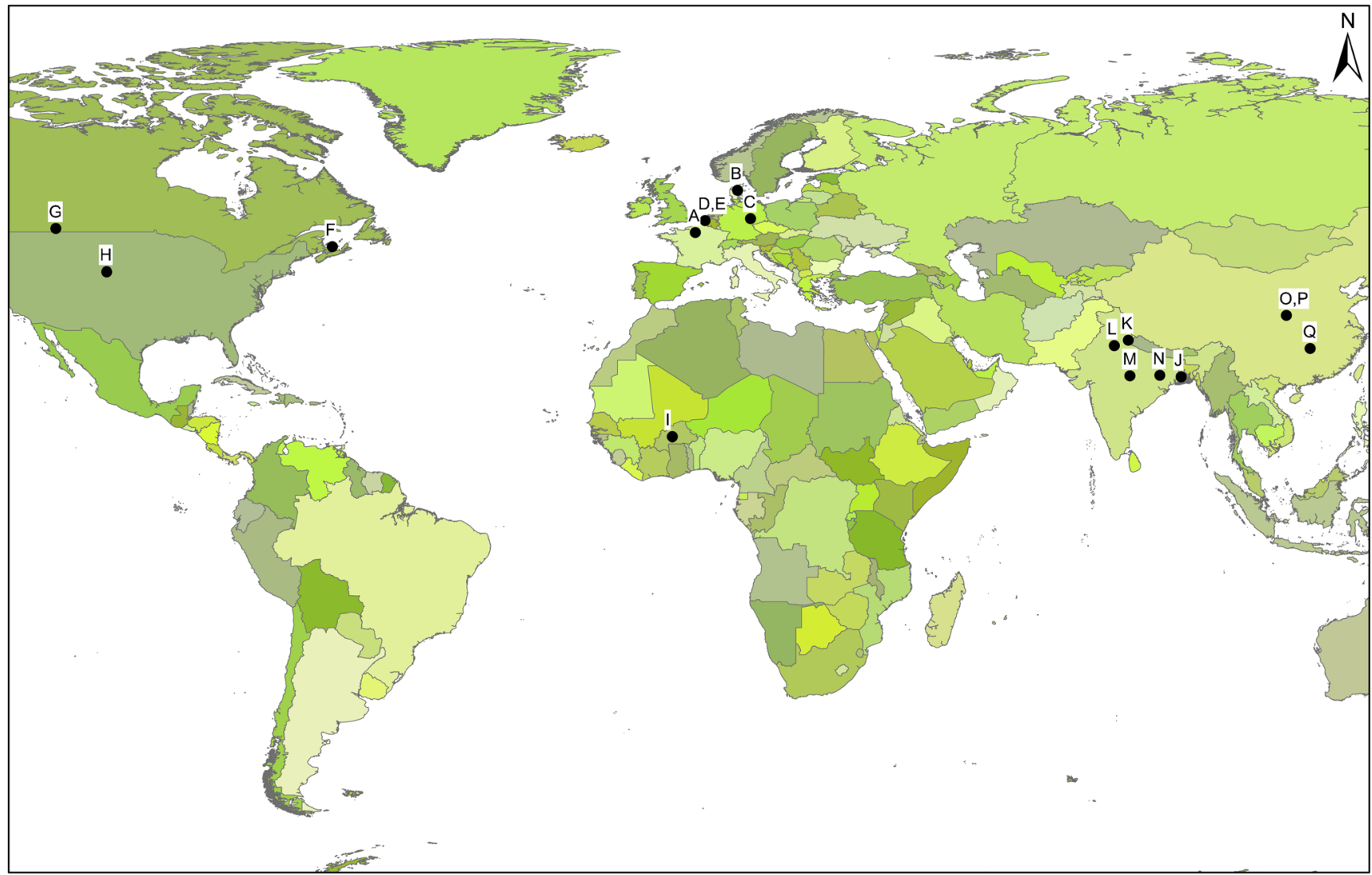

Fig. 3 Locations of the selected long-term experiments. The map IDs (letters) are stated in Table 1 (map: Esri, DeLorme Publishing Company, CIA World Factbook (2011))

was also reported in an older review on the impact of exogenous OM (Khaleel et al. 1981).

In order to examine the impact of the exogenous OM quality more closely, an indicator of residual OC (IROC in \%) from exogenous OM application developed by Lashermes et al. (2009) under laboratory conditions was used. It is calculated as follows:

$\mathrm{IROC}=445+0.5 \mathrm{SOL}-0.2 \mathrm{CEL}+0.7 \mathrm{LIC}-2.3 \mathrm{C} 3 \mathrm{~d}$

where SOL, CEL and LIC are the lab-derived soluble, cellulose and lignin + cutin-like fractions of total OM according to the Van Soest procedures (van Soest 1963; van Soest and Wine 1967), respectively, and C3d is the proportion of amendment-derived OC mineralized after 3 days of incubation in the lab. The indicator basically denotes the proportion of exogenous $\mathrm{OC}$ contribution to soil OC, which then is referred to as residual OC. Based on data from a variety of organic wastes, they employed information on biochemical carbon fractions and carbon mineralization to predict residual $\mathrm{OC}$ after mineralization of more easily biodegradable organic fractions. According to Lashermes et al. (2009), compared with field data of residual $\mathrm{OC}$, values provided by the indicator appeared overestimated, which may be due to faster degradation of exogenous OC in the field than in the lab. However, Peltre et al. (2012) used IROC partition coefficients in a model for four long-term experiments with different durations and from different countries and found only slightly larger errors than when using partition coefficients fitted from local soil data.

Relative percent change in OC represents the development of OC in amended vs. control plots, which have not received organic amendments. This increase in OC is hence owed to the impact of such applications. The necessary IROC data were only available for the French experiment (Qualiagro). Where no measurements were available, indicator values for the different types of amendments applied were taken from an online tool (Peltre 2012) to predict the evolution of OC following exogenous OM application, and residual OC was calculated for all treatments. Indicator values reported on this online tool are e.g. $67 \%$ for cattle (or dairy) manure, $54 \%$ for slurry, $55 \%$ for plant material and $82 \%$ for green waste compost. Using these indicator values, the amount of potentially efficient residual $\mathrm{OC}$ from the exogenous OM application was calculated. Addition of the respective amounts of residual OC with amendments as it is shown in Fig. 5 had a weak significant effect on relative percent change in OC 


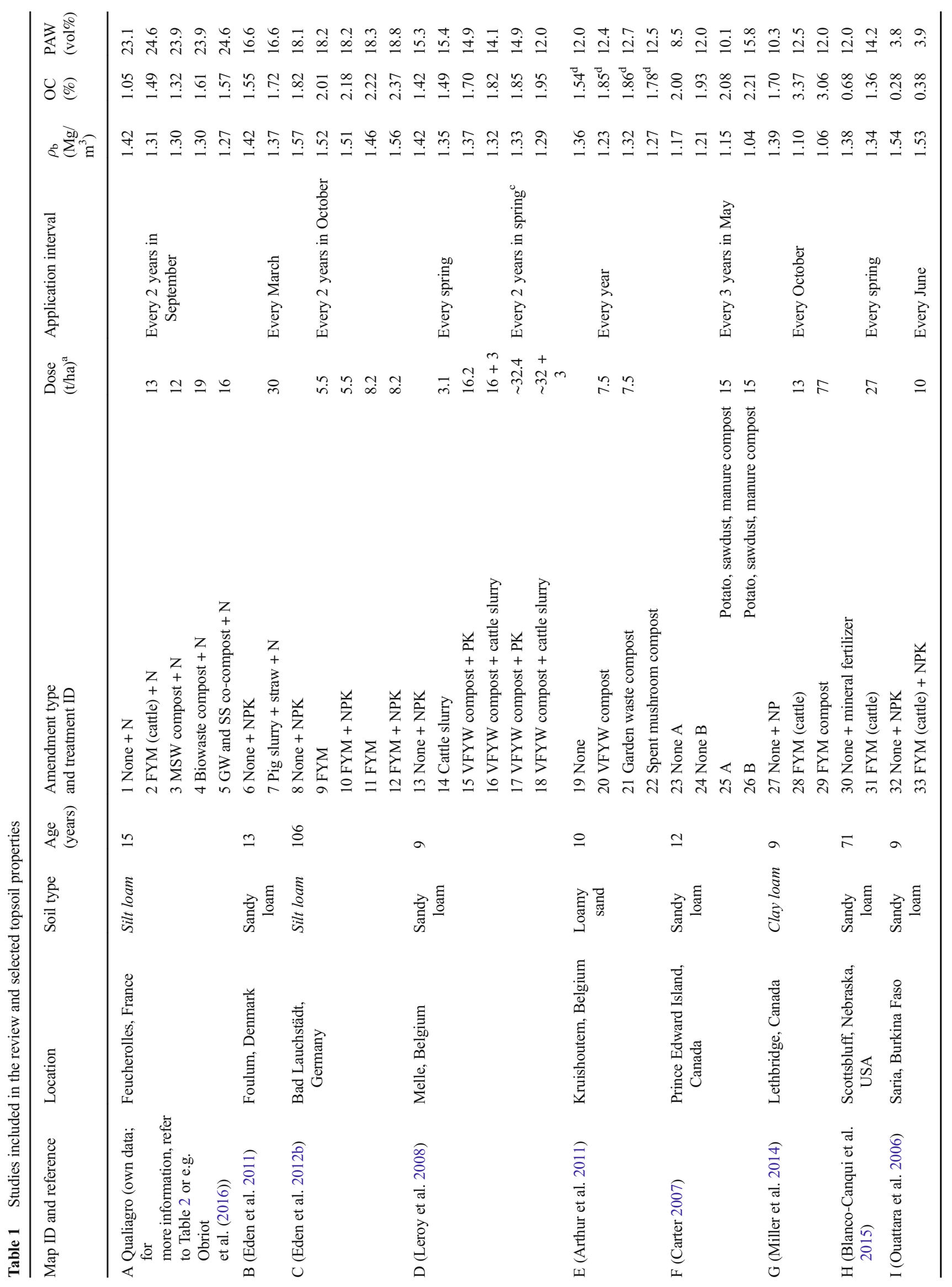




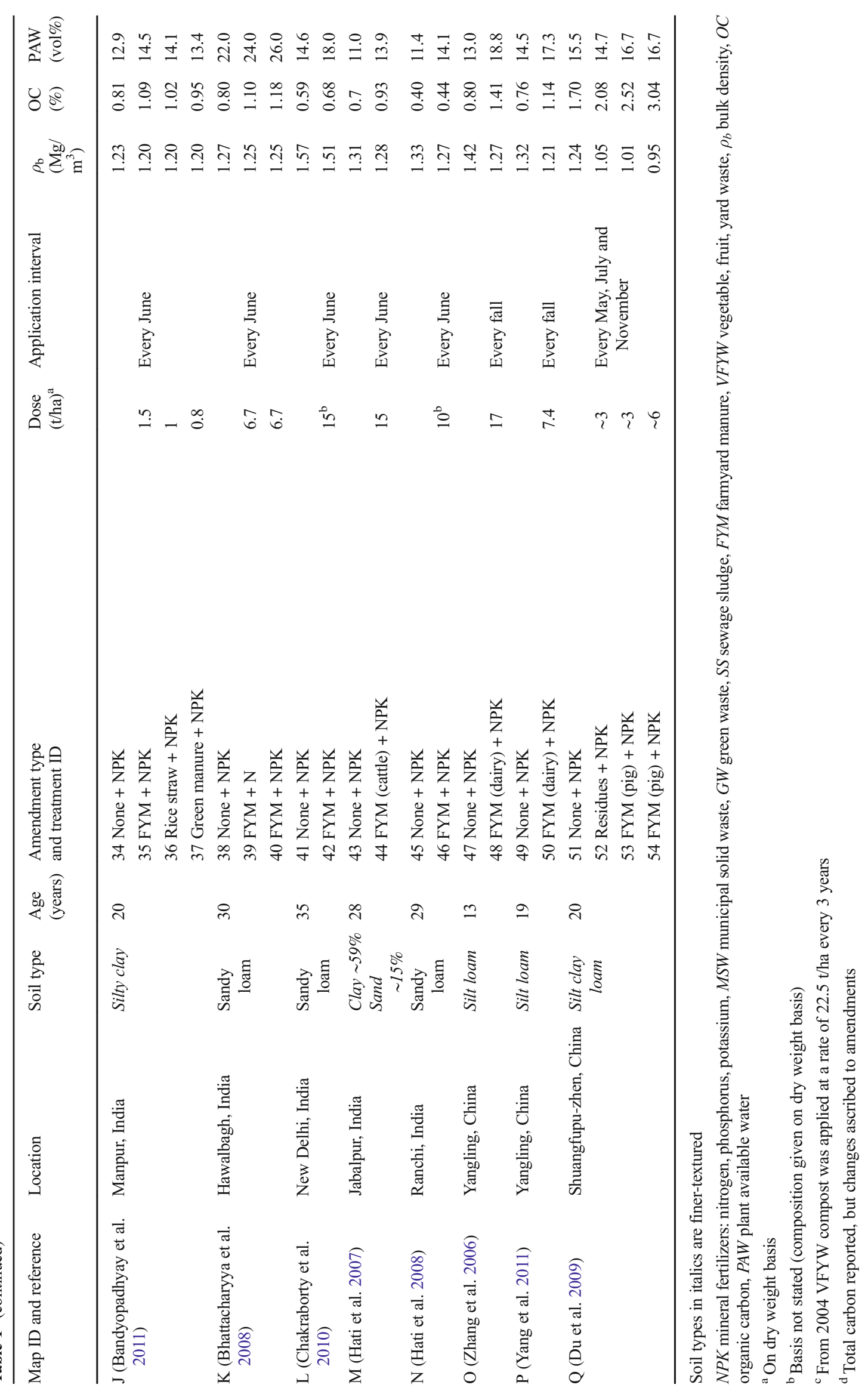




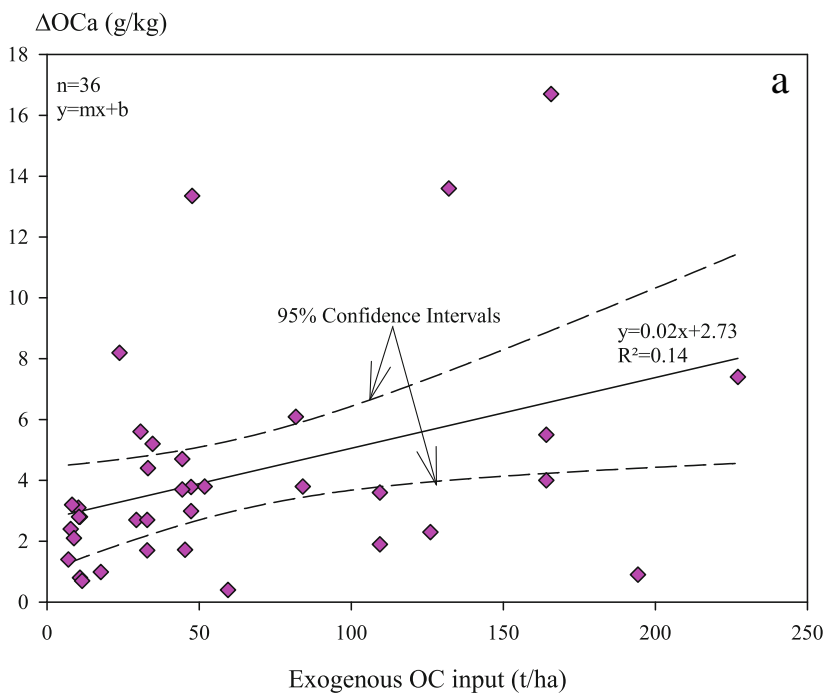

$\Delta$ Bulk Density, $\rho_{\mathrm{b}}$

$\left(\mathrm{Mg} / \mathrm{m}^{3}\right)$

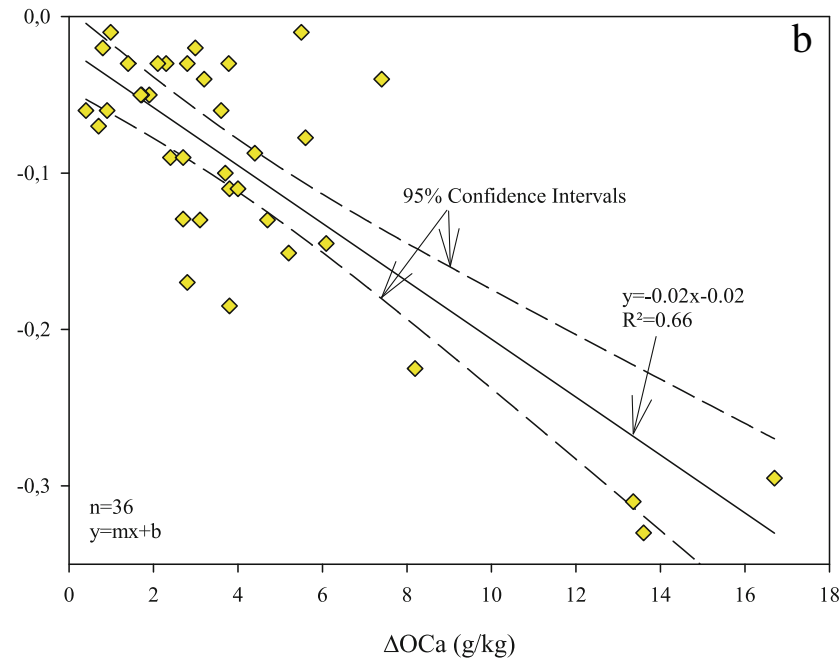

Fig. 4 Absolute change in OC as a function of exogenous OC input (a) and absolute change in bulk density as a function of absolute change in OC (b) for topsoil data from control vs. amended plots of all experiments listed in Table 1 ( $\triangle O C a$ absolute change in organic carbon)

$\left(p<0.05^{*}\right)$ and absolute change in OC in grams per kilogram $\left(p<0.05^{*}\right)$. These $p$ values are in fact lower than those determined for exogenous OC input (Fig. 4a); hence, residual OC may be a more useful parameter to highlight an impact of exogenous OM application on OC. Being based on the fractions and decomposability of the organic material added to soil, this method accounts for the quality of the amendment, not just the quantity applied. The results achieved with this method might be better if the IROC was based on individually measured data instead of averaged values as reported in the online tool.

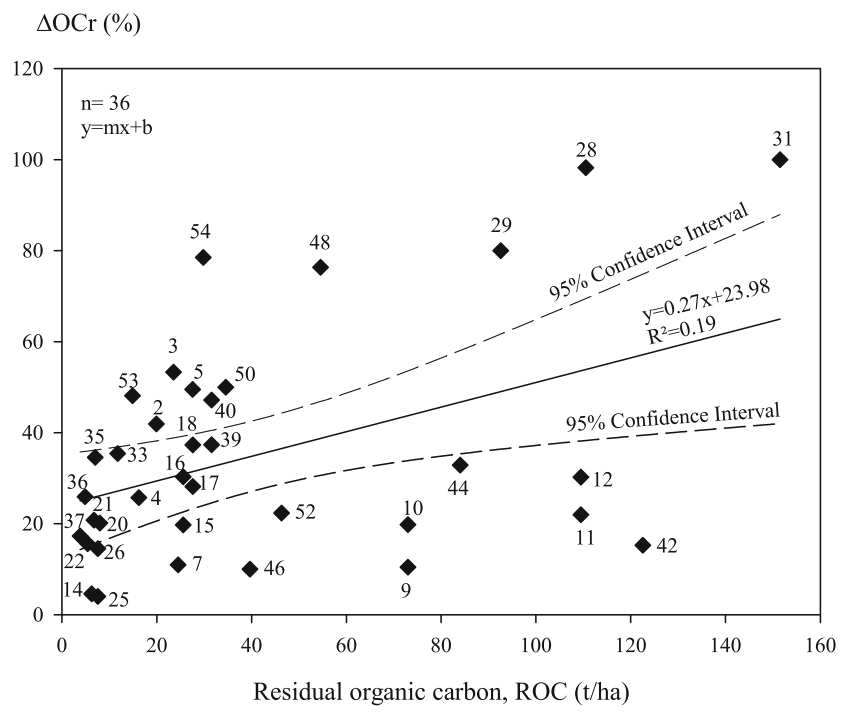

Fig. 5 Percent change in OC as function of input of residual OC applied with the organic amendment. Treatment IDs are stated next to each data point (ROC residual organic carbon, $\triangle O C r$ relative change in organic carbon)
The data seem grouped though, as can be seen in Fig. 5; nonetheless, no impact of texture (coarser vs. finer), climate (according to Köppen) or type of organic amendment could be discerned (data not shown). Regarding the type of organic amendment, it can be stated that most of the manure treatments are outside of the confidence intervals, as well as half of the compost treatments. Due to this and the fact that most compost treatments were within the narrow range of $\sim 0-40 \mathrm{t} / \mathrm{ha}$ residual OC, no conclusions based on input type were drawn. The scatter can be observed by comparing the numbers indicated near each symbol with the treatment ID from Table 1. Other aspects than those investigated may play a role and cause these differences.

\subsection{Volumetric versus gravimetric water content}

Volumetric, $\theta$, and gravimetric, $w$, water content, are both used to describe the water holding capacities of soils. Gravimetric water content can be determined in the laboratory by weighing soil samples at different moisture levels. The volumetric water content is related to $w$, by the soil bulk density, $\rho_{\mathrm{b}}$, as follows:

$\theta=\rho_{b} * w$

assuming that the density of water is $\sim 1 \mathrm{~g} / \mathrm{cm}^{3}$ (e.g. Brady and Weil 2008). When using $\theta$, the conversion to water depth (stated in $\mathrm{mm}$ ) per soil horizon is straightforward. And since available water holding capacity (AWHC) is generally expressed in millimetre (water depth), volumetric water 
Gravimetric water content

(relative percent change)
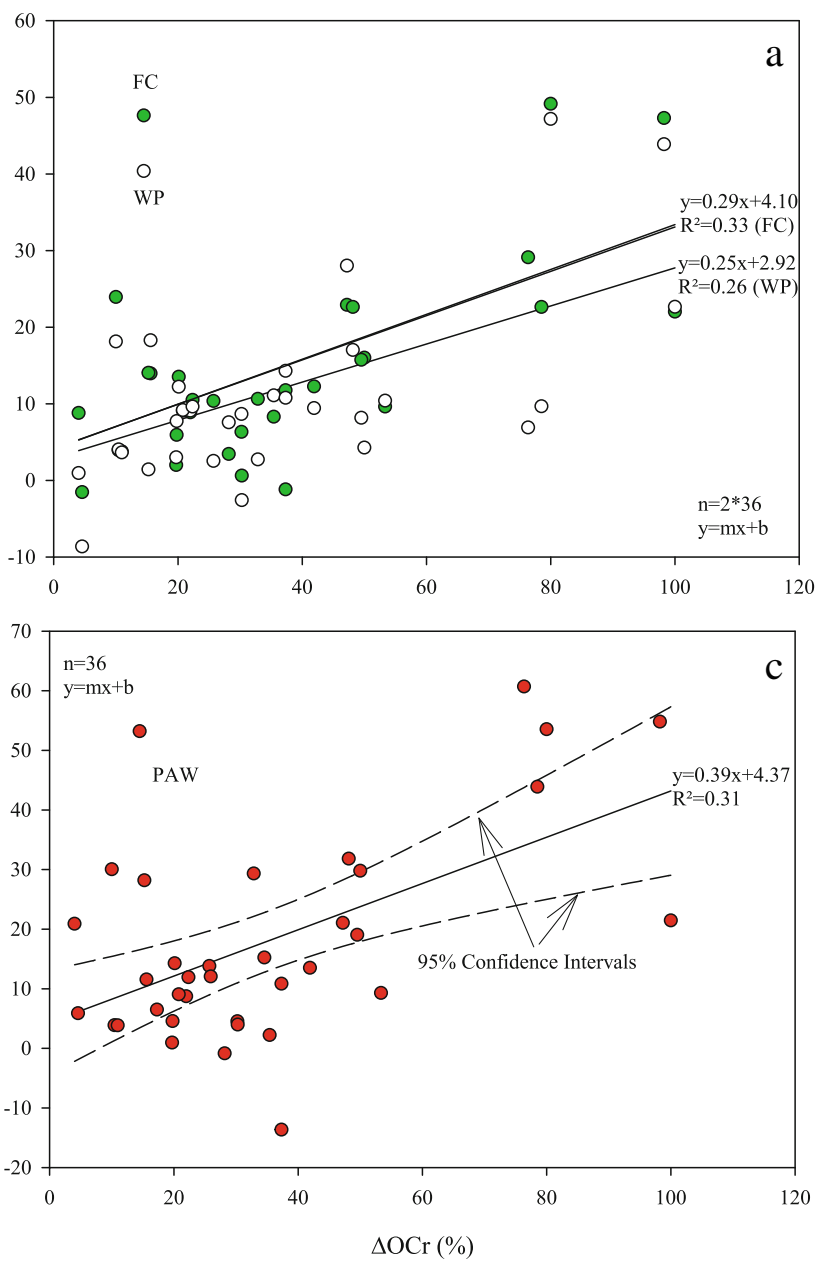

Fig. 6 Relative percent changes in water content (a, b FC (green) and WP (white); $\mathbf{c}, \mathbf{d}$ PAW (red)) as a function of relative percent changes in $\mathrm{OC}$ for gravimetric water content $(\mathbf{a}, \mathbf{c})$ as opposed to volumetric water

content allows for comparison between sites or calculation of irrigation needs:

$$
\mathrm{AWHC}=\left(\theta_{\mathrm{FC}}-\theta_{\mathrm{WP}}\right) * L
$$

where $L$ is the length or soil depth (in $0.1 \mathrm{~m}$ ) of interest.

Due to the inclusion of soil bulk density, stating volumetric water content may also provide a different picture than when reporting gravimetric water content.

For the data reviewed here, the differences between gravimetric and volumetric water contents in the relation to relative changes in soil OC are depicted in Fig. 6a, b (FC and WP) and Fig. 6c, d (PAW). There is a significant positive linear relationship between relative changes in $\mathrm{OC}$ and gravimetric water content for FC $(p<0.001 * * *)$, WP $(p<0.01 * *)$ and PAW $(p<0.001 * * *)$. In contrast, there is no relationship between $\Delta \mathrm{OCr}$ and volumetric water content at FC and WP (both $p>0.05$ ), but a seemingly significant positive relationship
Volumetric water content

(relative percent change)
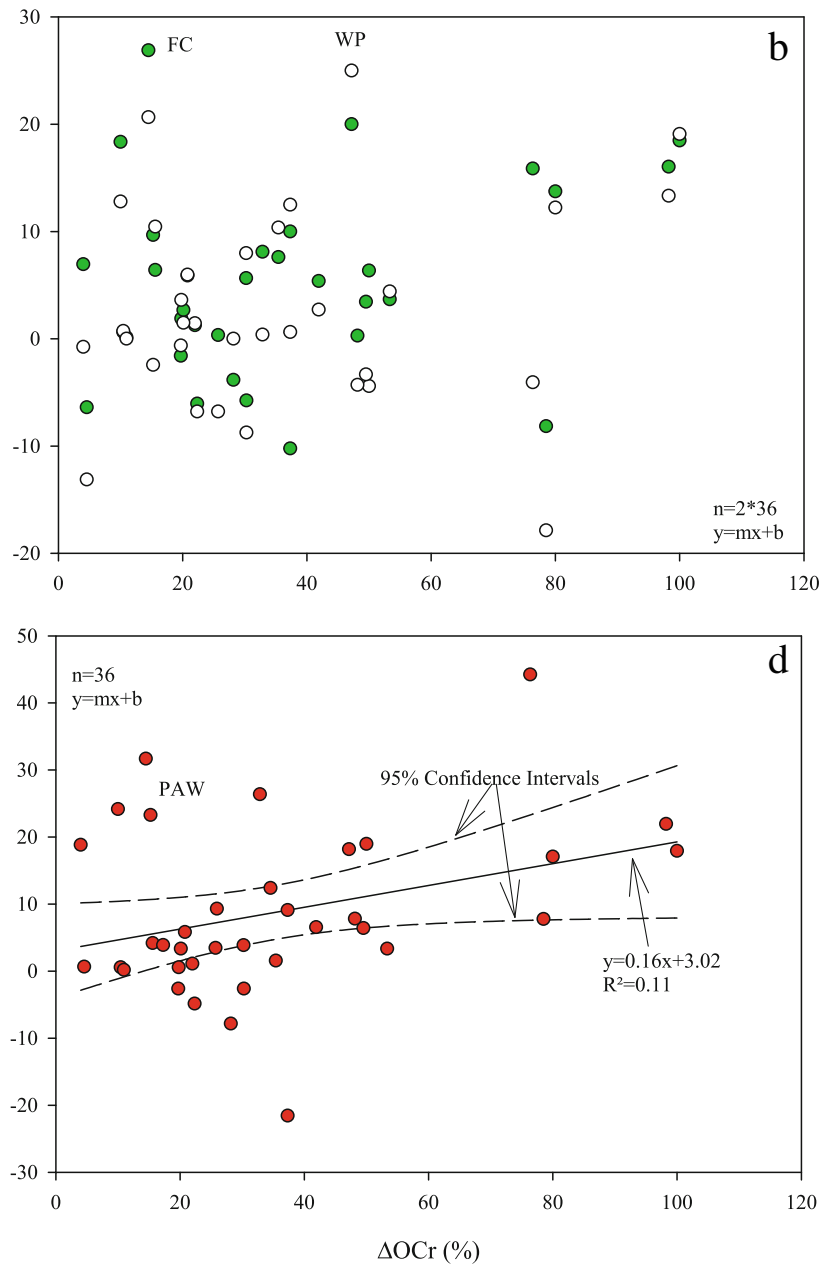

content (b, d), always calculated for the respective incorporation or sampling depth $(\triangle O C r$ relative change in organic carbon, $F C$ field capacity, $W P$ wilting point, $P A W$ plant available water)

was found for PAW ( $p=0.052)$. When including bulk density in the expression of soil water content, there no longer is a statistically significant positive effect of the relative percent change in OC content at FC and WP; for PAW, the degree of significance is reduced from strong to weak. This comparison suggests that gravimetric water content may not be suitable to highlight a positive influence of exogenous OM in respect to PAW, because density is disregarded, which in itself is strongly affected by the amendments (Fig. 4b). It may rather create an incorrect impression of the impact of exogenous OM addition and the related change in OC on PAW and moreover disagrees with the definition by Romano and Santini (2012) mentioned previously. The results in Fig. 6 demonstrate that volumetric water content is more appropriate in this context, as it also allows for comparisons of the impact of organic waste applications on soil water content (e.g. FC, WP, PAW). Therefore, in comparative studies, volumetric water content is advised, even though on the global scale 
considered here, the effects of exogenous OM on PAW are not always significant. This may drastically change though, when focusing on an individual location.

\subsection{Water holding capacity}

\subsubsection{Water retention at FC and WP}

$\mathrm{OC}$ and water contents at FC and WP changed with exogenous $\mathrm{OM}$ addition. With increasing difference in $\mathrm{OC}$ between control and amended treatments, the difference in total water holding capacity is expected to increase as well. This is owed to the simple fact that $\mathrm{OM}$ additions enhance macro-aggregate formation and stability, thus increasing the pore volume and simultaneously decreasing bulk density, which essentially increases the space available to hold water. Figure $6 \mathrm{~b}$ shows the relations between relative changes in soil OC and relative changes in FC as well as WP on a volumetric basis. Statistical analysis confirmed no correlation between relative changes in soil OC and relative changes in FC or WP. The relative percent changes in $\mathrm{OC}$ added through exogenous $\mathrm{OM}$ do not explain the relative percent changes in water retention at FC and WP. This may be due to management practices, different quality of amendment, impact of climate and induced hydrophobicity. However, neither residual OC serves as an explanatory parameter, nor are relative changes in $\theta$ at $\mathrm{FC}$ or WP linked to this portion of exogenous OM (data not shown). In spite of the lack of relation between relative changes in soil $\mathrm{OC}$ and relative changes in FC or WP (including decreases in FC or WP), total water holding capacity may still be improved via increases in the pore volume between $\mathrm{FC}$ and saturation (macropores).

\subsubsection{Water retention between FC and WP}

As can be seen in Fig. 6d, there is a positive linear relationship between the additional $\mathrm{OC}$ and relative percent changes in PAW. For 31 of 36 amended treatments, an increase in PAW was observed; in five cases, PAW decreased. Four of the cases with decreases in PAW in amended plots were encountered in a single study (Leroy et al. 2008): treatment IDs 15-18. However, this aspect was not part of their discussion, and hence, no potential reasons were mentioned. Therefore, it can only be hypothesised that the compost used contained hydrophobic OM. They investigated five amended treatments, of which four received compost with or without slurry addition and showed decreased PAW; the remaining treatment with increased PAW received only slurry (treatment ID 14). Since 31 amended plots displayed increases in PAW, it shows that - according to the expectation-exogenous OM addition generally improves PAW.
Distinguishing between the two types of amendments most often applied (composts and manures) in the studies revisited does not reveal any notable differences on PAW (data not shown). The stabilization of organic materials during the composting process did not exert a discernible effect on percent changes in PAW compared to fresh organics contained in an untreated product like manure. The differences in the effects of fresh vs. composted amendments may have further been masked, e.g. since manure (i.e. fresh) is often stockpiled, left to rot and decompose before field application. However, one type of compost led to decreases in PAW (vegetable, fruit and garden waste compost in treatment IDs 15-18), while there was no such case for manure among the reviewed studies. Overall, more studies would be needed to make a comparison between amendment types, e.g. $n \geq 30$ of each.

The influence of exogenous $\mathrm{OM}$ addition on water available for plants changes, when setting FC at $\mathrm{pF} 2$. Seven of the 17 studies report water content at both, $\mathrm{pF}$ 2 and $\sim \mathrm{pF} 2.5$; these studies cover 19 amended treatments. When using pF 2 as FC, only one of the treatments (ID 18), previously found to negatively affect PAW, displays a reduced amount of water available for plants

Table 2 Influence of $\mathrm{pF}$ level of FC (2 or 2.5) for determination of relative percent changes in PAW

\begin{tabular}{|c|c|c|c|}
\hline Reference & $\begin{array}{l}\text { Treatment } \\
\text { ID }\end{array}$ & $\begin{array}{l}\text { Relative } \% \\
\text { change in PAW } \\
\text { with pF } 2\end{array}$ & $\begin{array}{l}\text { Relative } \% \\
\text { change in PAW } \\
\text { with pF } 2.5\end{array}$ \\
\hline \multirow[t]{4}{*}{ Qualiagro (own data) } & 2 & 6.4 & 6.5 \\
\hline & 3 & 5.0 & 3.3 \\
\hline & 4 & 4.7 & 3.5 \\
\hline & 5 & 7.0 & 6.4 \\
\hline Eden et al. (2011) & 7 & 1.4 & 0.2 \\
\hline \multirow[t]{4}{*}{ Eden et al. (2012b) } & 9 & 2.8 & 0.6 \\
\hline & 10 & 2.4 & 0.6 \\
\hline & 11 & 2.8 & 1.1 \\
\hline & 12 & 4.2 & 3.9 \\
\hline \multirow[t]{5}{*}{ Leroy et al. (2008) } & 14 & 9.5 & 0.7 \\
\hline & 15 & 8.4 & -2.6 \\
\hline & 16 & 7.4 & -2.6 \\
\hline & 17 & 6.3 & -7.8 \\
\hline & 18 & -4.2 & -21.6 \\
\hline \multirow[t]{3}{*}{ Arthur et al. (2011) } & 20 & -3.2 & 3.3 \\
\hline & 21 & 5.3 & 5.8 \\
\hline & 22 & -11.6 & 4.2 \\
\hline Ouattara et al. (2006) & 33 & 2.9 & 1.6 \\
\hline Hati et al. (2007) & 44 & 20.6 & 26.4 \\
\hline
\end{tabular}

Values in italic indicate the larger increase when comparing the two; for one treatment (ID 18), both changes are negative

$F C$ field capacity, $P A W$ plant available water 
compared to control (Table 2). Also, two of three compost-amended treatments by Arthur et al. (2011) (treatment IDs 20 and 22) display reduced PAW under these conditions (Table 2). However, the high sand content (c.f. Tables 1 and 4) may be the relevant soil property for treatments 20 and 22. In 13 treatments, relative percent changes for PAW are larger when using $\mathrm{pF} 2$ as FC, and for one treatment, the decrease is smaller (Table 2). This means that the additional pore volume in the range between $\sim 9.5$ and $30 \mu \mathrm{m}$ equivalent pore diameters (Eq. 1) can have a pronounced effect on PAW. Hence, the data from the long-term experiments confirm that the suction threshold definition and the actual measured water content at FC have a big influence on PAW.

The correlation between relative percent change in PAW and total input of exogenous $\mathrm{OC}$ or residual $\mathrm{OC}$ in the amended systems was not significant (data not shown). Consequently, the total OC input and its residual fraction are relevant but not statistically significant indicators for the impact of a given amendment on the dynamics of FC and WP. Other variables of the experiments investigated must play a role; the various interactions are too complex and cannot be described merely by amendment.

\subsection{Predicting soil water retention}

\subsubsection{Impact of texture and carbon content}

Soil water retention is a crucial property and ecosystem service in regard to agricultural land use. A drying branch of the equilibrium water retention can be measured relatively reliably and reproducibly in the laboratory, but the method is time-consuming and special equipment is needed (Dane and Hopmans 2002). The most common approach is based on sand boxes and pressure plates, where many samples can be run simultaneously, but equilibration takes time to determine only a few points of the water retention function. A faster approach applies the evaporation method, but multiple set-ups are needed to run samples simultaneously. In order to avoid the laborious measurements and to be able to deal with large data sets, numerous hydraulic PTFs have been proposed, which should provide approximations of the soil hydraulic properties (e.g. Hudson 1994; Pollacco 2008; Rawls et al. 2003; Wosten et al. 2001). Number and size distribution of pores as well as soil-specific surface area of solids greatly affect the water holding capacity (Gupta et al. 1977; Haynes and Naidu 1998). Pore sizes and surface areas themselves are affected by $\mathrm{OC}$ in multiple ways (e.g. via aggregation, bulk density, biological activity). Water holding capacity around FC is primarily influenced by the volume of pores smaller than $\sim 30 \mu \mathrm{m}$ (depending on the definition of FC, c.f. Eq. 1), whereas the surface area and thickness of water films determine water holding capacity of the soil for $\mathrm{pF}$ values around WP.

The PTFs proposed by Rawls et al. (2003) in particular take $\mathrm{OC}$ into account and were derived for $\mathrm{FC}($ at $-33 \mathrm{kPa})$ and $\mathrm{WP}$ (at $-1500 \mathrm{kPa}$ ) as stated in the following:

$$
\begin{aligned}
& \mathrm{FC}=29.7528+10.3544\left(0.0461615+0.290955 x-0.0496845 x^{2}+0.00704802 x^{3}+0.269101 y-\right. \\
& 0.176528 x y+0.0543138 x^{2} y+0.1982 y^{2}-0.060699 y^{3}-0.320249 z- \\
& 0.0111693 x^{2} z+0.14104 y z+0.0657345 x y z-0.102026 y^{2} z-0.04012 z^{2}+0.160838 x z^{2}-0.121392 y z^{2}- \\
& \left.0.0616676 z^{3}\right)
\end{aligned}
$$

$\mathrm{WP}=14.2568+7.36318\left(0.06865+0.108713 x-0.0157225 x^{2}+0.00102805 x^{3}+0.886569 y-\right.$

$0.223581 x y+0.0126379 x^{2} y-0.017059 y^{2}+0.0135266 x y^{2}-0.0334434 y^{3}-0.0535182 z-0.0354271 x z-$

$0.00261313 x^{2} z-0.154563 y z-0.0160219 x y z-0.0400606 y^{2} z-0.104875 z^{2}+0.0159857 x z^{2}-$

$\left.0.0671656 y z^{2}-0.0260699 z^{3}\right)$

where $x=-0.837531+0.4301830 C ; y=-1.40744+$ 0.0661969 (clay); $z=-1.51866+0.0393284$ (sand); $0.02<$ OC $<28.44 ; 0.0<$ clay $<90$; and $0.7<$ sand $<95$.

The input data needed include contents of sand, clay and $\mathrm{OC}$ and thus account for the effect of OC content on the relationship between textural components and water retention. Table 3 gives measured and predicted values for FC and WP for a subset of 11 of the studies revisited, which reported all textural information necessary for using the PTFs of Rawls et al. (2003). The predictions were derived for the control soils and those treatments inducing the largest increase in OC for each of these studies. For five soils, the predicted values are fairly close to the measured ones at both points for both treatments (control and amended). In four cases on three soils, FC is larger than the given deviation (root-mean-square error of the prediction); regarding WP, this is the case in eight instances on five soils. The predictions were particularly poor for a clayey soil from India (Hati et al. 2007) and lead to a predicted reduction in PAW for the amended 
Table 3 Measured (m) and predicted (p) values (vol\%) of FC, WP and calculated PAW of control and the treatment inducing the largest increase in OCU Using the equations given by Rawls et al. (2003)

\begin{tabular}{llllllll}
\hline Reference & Treatment & $\mathrm{FC}_{\mathrm{m}}$ & $\mathrm{FC}_{\mathrm{p}}$ & $\mathrm{WP}_{\mathrm{m}}$ & $\mathrm{WP}_{\mathrm{p}}$ & $\mathrm{PAW}_{\mathrm{m}}$ & $\mathrm{PAW}_{\mathrm{p}}$ \\
\hline Qualiagro (own data) & 1 Control & 33.3 & 33.9 & 10.1 & 6.7 & 26.2 & 23.1 \\
& 4 Amended & 34.5 & 35.6 & 10.6 & 7.4 & 26.6 & 23.9 \\
Eden et al. (2011) & 6 Control & 23.2 & 19.6 & 6.6 & 7.9 & 16.6 & 11.8 \\
& 7 Amended & 23.2 & 20.0 & 6.6 & 8.0 & 16.6 & 12.0 \\
Eden et al. (2012b) & 8 Control & 31.9 & 34.3 & 13.8 & 16.6 & 18.1 & 17.8 \\
& 12 Amended & 33.7 & 35.8 & 14.9 & 17.1 & 18.8 & 18.7 \\
Leroy et al. (2008) & 13 Control & 31.3 & 26.8 & 16.0 & 9.7 & 15.3 & 17.1 \\
& 18 Amended & 28.1 & 27.8 & 16.1 & 10.1 & 12.0 & 17.7 \\
Arthur et al. (2011) & 19 Control & 18.7 & 16.9 & 6.7 & 6.1 & 12.0 & 10.8 \\
& 21 Amended & 19.8 & 18.2 & 7.1 & 6.5 & 12.7 & 11.7 \\
Carter (2007) & 24 Control & 21.2 & 25.3 & 9.2 & 10.1 & 12.0 & 15.2 \\
Ouattara et al. (2006) & 26 Amended & 26.9 & 25.9 & 11.1 & 10.3 & 15.8 & 15.6 \\
& 32 Control & 12.2 & 22.6 & 8.4 & 8.8 & 3.8 & 13.8 \\
Hati et al. (2007) & 33 Amended & 13.2 & 23.3 & 9.3 & 9.2 & 3.9 & 14.1 \\
& 43 Control & 33.7 & 44.6 & 24.0 & 30.7 & 9.7 & 13.9 \\
Hati et al. (2008) & 44 Amended & 40.0 & 44.3 & 26.1 & 30.5 & 13.9 & 13.8 \\
Zhang et al. (2006) & 45 Control & 23.3 & 26.3 & 11.9 & 16.4 & 11.9 & 9.9 \\
Du et al. (2009) & 46 Amended & 27.6 & 26.7 & 13.4 & 16.5 & 14.1 & 10.2 \\
& 47 Control & 31.5 & 30.4 & 18.5 & 15.5 & 13.0 & 14.9 \\
& 48 Amended & 36.5 & 31.3 & 17.8 & 15.7 & 18.8 & 15.6 \\
& 51 Control & 40.8 & 34.0 & 25.3 & 18.0 & 15.5 & 16.0 \\
& 54 Amended & 37.5 & 36.0 & 20.8 & 18.3 & 16.7 & 17.7 \\
\hline
\end{tabular}

Predicted values in italic indicate deviations larger than the provided root-mean-square errors of 6.2 (for FC), 3.1 (for WP) and 5.8 (for PAW) vol\% from measured ones

$F C$ field capacity, $W P$ wilting point, $P A W$ plant available water soil. Three studies from continental Europe, one from North America and one from China were well predicted; two studies from Burkina Faso and India had the poorest predictions. However, there were also shortcomings for the predictions in some studies from continental Europe. Therefore, similar pedoclimatic conditions as those studied by Rawls et al. (2003) had no obvious impact on the prediction accuracy. This is exemplified by two studies conducted near Ghent, Belgium, where one was well predicted unlike the other.

Overall, there are no trends regarding overestimation or underestimation by the PTF of the values for FC and WP. Of a total of 44 PTF-derived water contents (Table 3: FC and WP for 11 experiments and two treatments each), 32 were well predicted and 12 deviated by more than the root-mean-square error indicated by the authors for these PTFs. Regarding PAW, the PTFs well predicted 20 of 22 values; for one study (Ouattara et al. 2006), PAW was overestimated, which, however, is rooted in the overestimation of FC. Hence, the PTFs provided by Rawls et al. (2003) can be useful in approximating FC, WP and moreover PAW in experiments with differing OC contents, with some exceptions though. In regard to PAW, it is important to point out though that the PTFs usually lead to increased PAW. Hence, it is necessary to note the one exception (Hati et al. 2007) in Table 3, which displayed a slightly higher PAW for the control; this may be linked to the high clay content. The data by Leroy et al. (2008) with reduced PAW in compost-amended soils were not well predicted. Except for these studies, the data here confirmed their conclusion (Rawls et al. 2003) that water retention at $\mathrm{FC}$ is more strongly affected by OC content than that at WP, which means increases in PAW. Including $\mathrm{OC}$ content in their functions led to a larger decrease in root-mean-square error at $\mathrm{FC}$.

Furthermore, errors and deviations may occur due to the fact that different particle size classes with different boundaries were applied by the different authors when determining texture, this cannot be made uniform afterwards. Moreover, the boundaries of textural classes may differ in grain size from those applied for the creation of these PTFs (silt size: $50-2 \mu \mathrm{m}$ ), but this information is not always included in the studies. Additionally, the slightly differing $\mathrm{pF}$ levels for determining the values of 


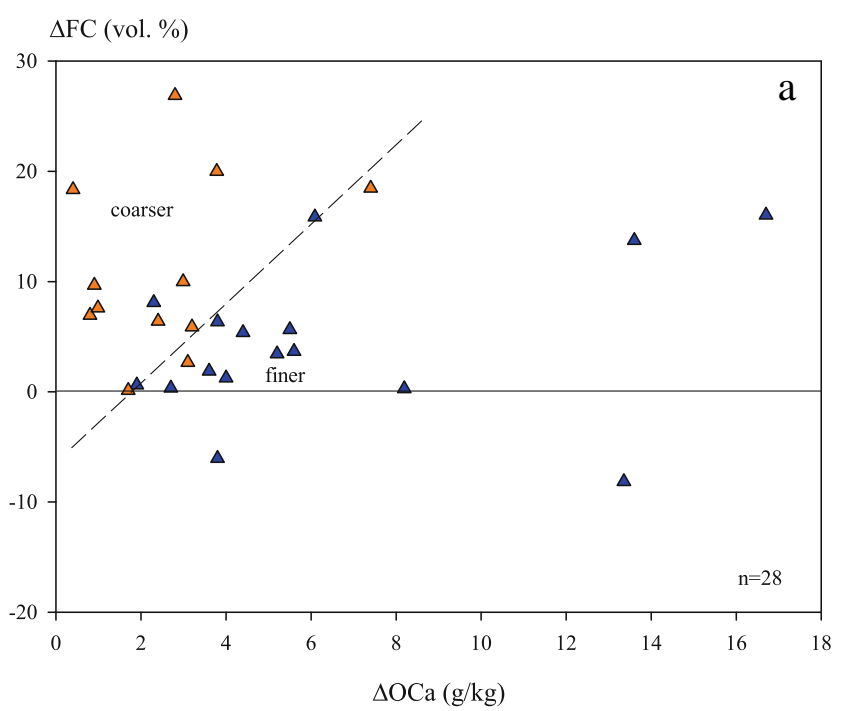

Fig. 7 Relative percent changes in volumetric (a) FC and (b) WP for finertextured (blue symbols) and coarser-textured (orange symbols) soils as a function of the absolute change in soil $\mathrm{OC}$ due to amendment. The dashed
$\Delta \mathrm{WP}($ vol. \%)

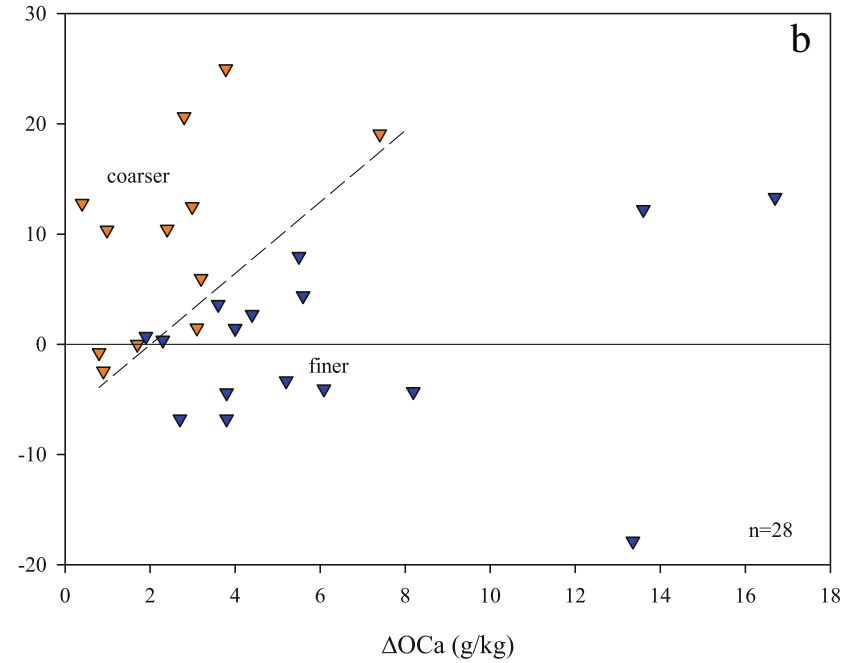

lines roughly divide coarser- from finer-textured soils in both $(\mathbf{a}, \mathbf{b})$. Data from Leroy et al. (2008) are excluded ( $F C$ field capacity, $W P$ wilting point, $\triangle O C a$ absolute change in organic carbon)
FC and WP used by the various authors could cause deviations regarding the prediction accuracy, but no consistent higher or lower water contents depending on the $\mathrm{pF}$ actually measured were found.

\subsubsection{Impact of organic waste addition}

Some 35 years ago, Khaleel et al. (1981) published a widely cited review on the impact of organic waste applications on soil physical properties, also addressing water holding capacity (on a weight basis). They concluded that $80 \%$ of the observed variations in percent increases in water holding capacity could be explained by texture and OC. More specifically, they observed that

1. Increases in water holding capacity at FC and WP are larger for coarser-textured soils than for finer-textured soils.

2. For finer-textured soils, increases in $\%$ water holding capacity are larger at FC than at WP.

3. For coarser-textured soils, the sand percentage produces larger increases in water holding capacity at WP than at FC.

They continued to reason that with equal increases at FC and WP, no net gain might be achieved in PAW. And since increases in OC decrease bulk density, this decrease might counterbalance an amendment-induced increase in PAW on a weight basis. However, in their study, gravimetric water content is reported which does not take bulk density into account, whereas in the present study, volumetric water content is used.

The key findings taken from their study were further examined and reassessed using the independent data compiled in this review; instead of gravimetric, the volumetric water contents were used. The data set was divided according to texture:

Relative changes in water content (vol. \%)

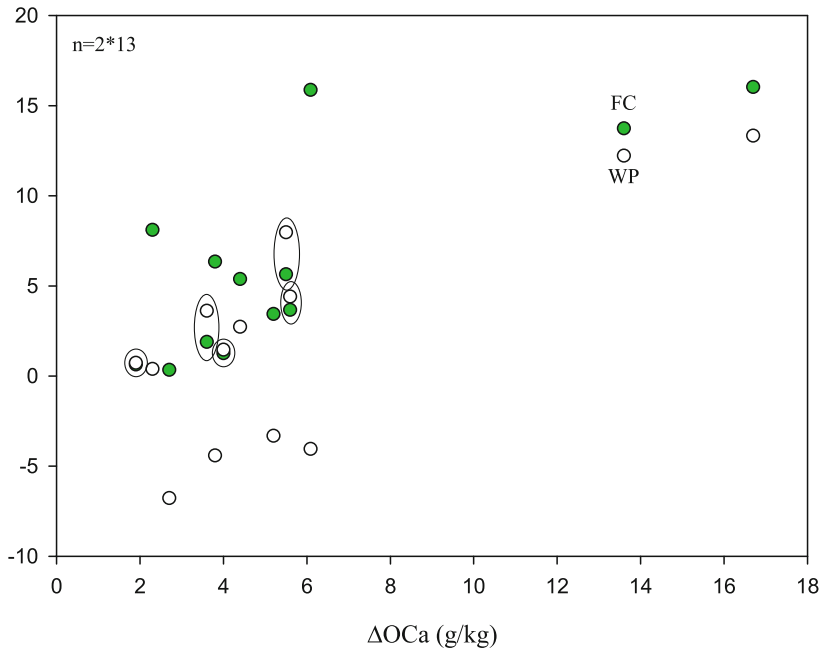

Fig. 8 Relative percent changes in volumetric water content at FC (green) and WP (white) for finer-textured soils as function of absolute changes in soil OC. Data pairs with larger increases at WP are circled. Data from Du et al. (2009) excluded ( $F C$ field capacity, WP wilting point, $\triangle O C a$ absolute change in organic carbon) 
finer and coarser. Sandy loams for instance are considered as coarser-textured, while silt loams are considered as finertextured soils (c.f. Table 1). Two studies are not included in Fig. 7, Bandyopadhyay et al. (2011) did not report FC or WP, and in the study of Leroy et al. (2008), the reductions in FC and PAW cannot be explained. Concerning statement 1 of Khaleel et al. (1981), there appears to be a trend confirming larger percent increases in FC and WP for coarser-textured soils (Fig. 7). Dashed lines in Fig. 7a, b roughly separate coarser- and finer-textured soils. It shows that relative changes in water content at FC and WP are larger for coarser-textured soils, already at small absolute changes in OC.

Regarding statement 2, Fig. 8 illustrates relative changes at FC and WP for finer-textured soils, but unlike in Fig. 7, data pairs of individual studies are discernible. Figure 8 shows larger increases for FC than for WP for most soils. However, this is not true for those from Eden et al. (2012b) (treatment
IDs 9-12) and one treatment (ID 4) in Qualiagro, which are circled in Fig. 8. Both of these experiments are located on silt loam loess soils and contain ca. 8 and $15 \%$ sand, respectively. For Du et al. (2009), two of three treatments showed reductions at both, FC and WP, and are therefore not included in Fig. 8, as it makes no sense to look e.g. at smaller decreases. Nonetheless, statement 2 does not hold true for all treatments in these experiments. Also, when looking at gravimetric water content (data not shown) in this context, the state-(8) ment cannot be fully confirmed either.

Regarding the last statement of Khaleel et al. (1981), it is necessary to employ the PTFs that they produced for relative percent increase in gravimetric water holding capacity at $\mathrm{FC}$ and $\mathrm{WP}$, here referred to as $\mathrm{FC}_{\mathrm{G}}$ and $\mathrm{WP}_{\mathrm{G}}$, using absolute change in $\mathrm{OC}$ and sand content. The equations are stated in the following:

$\begin{aligned} \Delta \mathrm{FC}_{\mathrm{G}} & =\exp \left[1.09+2.141(\Delta \mathrm{OCa})-0.4091(\Delta \mathrm{OCa})^{2}-0.0167(\text { sand })+0.00038(\text { sand })^{2}\right] \\ \Delta \mathrm{WP}_{\mathrm{G}} & =\exp \left[1.115+2.248(\Delta \mathrm{OCa})-0.442(\Delta \mathrm{OCa})^{2}-0.0443(\text { sand })+0.0007(\text { sand })^{2}\right]\end{aligned}$

In order to apply these PTFs, the subset of studies presenting sand content was used again and water holding capacities were transformed from volumetric to gravimetric. From a total of 22 predictions in Table 4, 14 were more than 5\% different

Table 4 Measured $(\mathrm{m})$ and predicted $(\mathrm{p})$ relative percent increases of gravimetric $\mathrm{FC}_{\mathrm{G}}$ and $\mathrm{WP}_{\mathrm{G}}$ of the treatment inducing the largest absolute increase in OC Using the equations given by Khaleel et al. (1981)

\begin{tabular}{llllll}
\hline Reference & Sand (\%) & $\Delta \mathrm{FC}_{\mathrm{Gm}}$ & $\Delta \mathrm{FC}_{\mathrm{Gp}}$ & $\Delta \mathrm{WP}_{\mathrm{Gm}}$ & $\Delta \mathrm{WP}_{\mathrm{Gp}}$ \\
\hline Eden et al. (2012b) & $\sim 8.9$ & 6.3 & 7.7 & 8.7 & 6.9 \\
Du et al. (2009) & 13.7 & 22.6 & 21.5 & 9.7 & 17.4 \\
Hati et al. (2007) & 14.6 & 10.6 & 4.0 & 2.7 & 3.0 \\
Qualiagro (own data) & 15.2 & 9.6 & 6.7 & 10.4 & 5.1 \\
Zhang et al. (2006) & 27.5 & 29.1 & 7.9 & 6.9 & 5.1 \\
Leroy et al. (2008) & 47.6 & -1.2 & 8.8 & 10.8 & 5.3 \\
Ouattara et al. (2006) & $\sim 54$ & 8.3 & 4.6 & 11.1 & 2.7 \\
Hati et al. (2008) & $\sim 58.1$ & 23.9 & 4.4 & 18.1 & 2.7 \\
Carter (2007) & 60 & 47.6 & 7.6 & 40.4 & 4.8 \\
Eden et al. (2011) & 77.6 & 3.8 & 9.9 & 3.6 & 8.3 \\
Arthur et al. (2011) & 85 & 9.1 & 21.3 & 9.2 & 21.8 \\
\hline
\end{tabular}

Predicted values in italic indicate deviations larger than $5 \%$ from measured ones; the studies are ordered according to increasing sand content $G$ gravimetric, $F C$ field capacity, $W P$ wilting point from the measured percent increases in FC or WP; in eight cases, the difference even was $10 \%$ or more. Even though these PTFs were specifically derived from the assessment of the impact of organic amendments on water holding capacity at FC and WP, they present rather large deviations from the actual values in a number of cases. Only for one study (Eden et al. 2012b), the predictions were fairly close to observed data for both, FC and WP; interestingly, this was the same study that disagreed with statement 2 .

Moreover, regarding statement 3, it showed that it was true only for soils with very large sand contents. Using a fictional range of absolute change in OC from 0.1 to $1.5 \mathrm{~g} / \mathrm{kg}$, the threshold sand content was between 86 and $83 \%$, respectively, when relative percent change in water content at WP became larger than at FC. Only one study (Arthur et al. 2011) was above the threshold sand content, and in two of three treatments (ID 21 and 22) in that study, relative percent change at WP was in fact larger than at FC.

Predictions might have been better if the conventions used to determine texture (grain sizes) had been the same throughout the present review, but also Khaleel et al. (1981) could not have corrected for this in their review, all the while silt sizes differed in their references (e.g. 20-2 $\mu \mathrm{m}$ (Williams and Cooke 1961) vs. 50-2 $\mu \mathrm{m}$ (Haghiri et al. 1978)). Consequently, already their PTFs were based on data with differing particle sizes. Another issue is that Khaleel et al. (1981) included a data set reporting moisture 
Relative changes

in PAW (vol. \%)

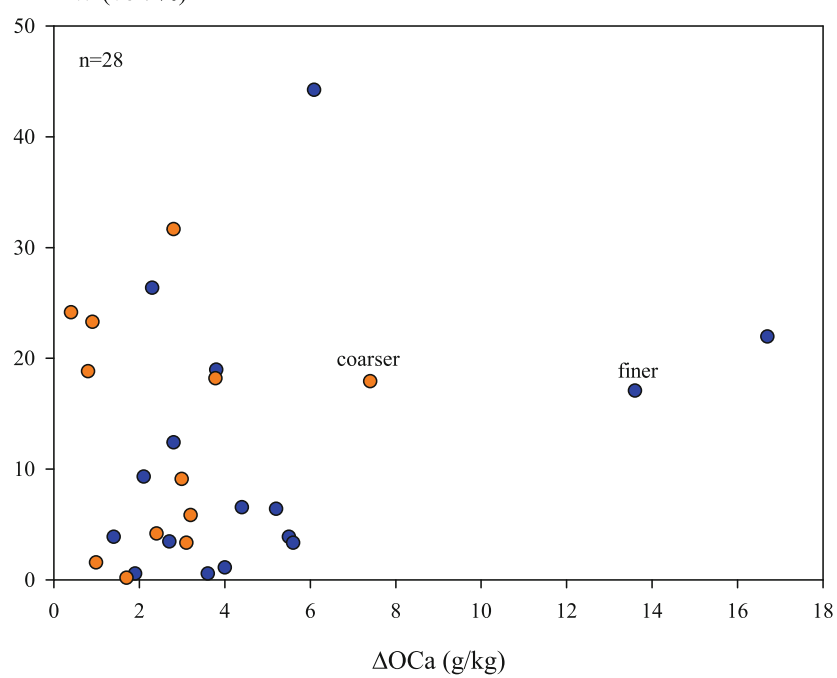

Fig. 9 Relative percent changes in PAW for soils with finer (blue) or coarser (orange) texture as function of absolute changes in soil OC. Data from two studies are excluded (Du et al. 2009; Leroy et al. 2008) (PAW plant available water, $\triangle O C a$ absolute change in organic carbon)

equivalent (Klute and Jacob 1950) instead of FC, which they also noted, but yet used. The method to obtain moisture equivalent had been described in 1907 (Briggs and McLane 1907) and was already disputed in 1926 (Thomas and Harris 1926). For another data set (Williams and Cooke 1961) from a long-term experiment, the information on water holding capacity and bulk density taken together appears incorrect and it remains unclear how Khaleel et al. (1981) interpreted these values as available water capacity (difference between moisture contents at FC and WP in $\%$ by weight). At least these data were not included in the deduced PTFs though.

Only three of the studies included by Khaleel et al. (1981) ran for 9 years or more: the aforementioned studies by Klute and Jacob (1950) and by Williams and Cooke (1961) could not be used here for the reasons stated earlier. With two of three studies eliminated, it appeared less meaningful to reuse the data reported by Khaleel et al. (1981).

Finally, the impact of finer- vs. coarser-textured soils on relative percent change in PAW was investigated (Fig. 9) to examine if any notable differences between them are discernible. However, both types of texture led to similar changes in PAW; the range was -21.6 to $48.1 \%$, while most studies showed increases between 0 and $30 \%$. Reductions in PAW were observed in two of the studies (Leroy et al. 2008; Du et al. 2009), which therefore are not included in Fig. 9. An impact of texture on changes in PAW cannot be determined here.

\subsection{Impact of climate}

The benefit of additional PAW may be of particular interest in areas with insufficient precipitation, regarding plant production, and where irrigation is being used. Figure 3 shows the locations of the various experiments, and it is obvious that different climates prevail in these places. However, not all studies report climatic information and that reported is inconsistent. Therefore, a web tool (Climate-Data), using a climate model and location data from the "OpenStreetMap project", was employed to determine the climatic data in a uniform manner according to Köppen (1918). Table 5 gives an overview of the climates encountered and shows that while $A$ to $G$ and $\mathrm{Q}$ do not feature dry seasons, $\mathrm{H}$ to $\mathrm{P}$ do. Hence, increased PAW might have even greater importance for the studies $\mathrm{H}$ to $\mathrm{P}$, particularly during drier seasons. At the same time, it is important to keep in mind that also, in areas considered as temperate without dry season, irrigation is often applied, in order to supply crops with sufficient water, optimize plant growth and maximize yields. Consequently, also, in these areas, increases in PAW are important.

Climate may affect PAW through its impact on OM, specifically its decomposition. According to Brady and Weil (2008), high temperatures (annual mean of $25-35^{\circ} \mathrm{C}$ ) and low rainfall lead to rapid $\mathrm{OM}$ decomposition, but low $\mathrm{OM}$ accumulation. For I, J, L, M and N, these conditions are met during the dry season, but not year-round. At lower temperatures or moister conditions, $\mathrm{OM}$ is more likely to accumulate. Anaerobic conditions promote $\mathrm{OM}$ accumulation at most temperatures, compared to aerobic conditions (Brady and Weil 2008). This means that for all experiments, favourable conditions for OM accumulation are - at least temporarily — given. Hence, structure formation and aggregation are supported, which may manifest itself in PAW increases through formation of pore space in the respective range. Figure 10a shows relative percent changes in PAW for soils with or without a dry season; when separating the two by a dashed line, an exception to this can be discerned. It may possibly be explained with its origin from a cold climate (cf. Table 5: F).

This climatic division moreover reveals a meaningful difference between the experiments: most of those above the dashed line have OC contents below $10 \mathrm{~g} / \mathrm{kg}$ for the control treatments (Table 1) and - where available-also lower initial OC contents. When depicting relative changes in PAW as a function of relative changes in OC, the exception is again the soil from $\mathrm{F}$, another soil from a cold climate: H, and a soil from a hot climate: I (Fig. 10b). This parameter (OC content of control) is easier to obtain than the climate classification as it is reported in all selected studies. Moreover, it appears reasonable that for soils lower in $\mathrm{OC}$, additional carbon input from organic amendments may have a more pronounced impact on structure forming potential affecting PAW than for soils with initially already higher $\mathrm{OC}$ content. Figure $10 \mathrm{~b}$ suggests that the same relative increase in OC may induce a larger relative increase in PAW in soils with initially low OC content. 
Table 5 Climate classification of all locations according to Köppen

\begin{tabular}{lllll}
\hline Map ID and reference & $\begin{array}{l}\text { Climate } \\
\text { classification }\end{array}$ & $\begin{array}{l}\text { Average } \\
\text { temperature }\left({ }^{\circ} \mathrm{C}\right)\end{array}$ & $\begin{array}{l}\text { Annual } \\
\text { precipitation }(\mathrm{mm})\end{array}$ & Description \\
\hline J (Bandyopadhyay et al. 2011) & Aw & 26.3 & $1545(1480)$ & Tropical savanna \\
I (Ouattara et al. 2006) & BSh & 27.6 & $777(800)$ & Arid steppe hot \\
L (Chakraborty et al. 2010) & BSh & 25.2 & $693(787)$ & Arid steppe hot \\
H (Blanco-Canqui et al. 2015) & BSk & 9 & $370(396)$ & Arid steppe cold \\
K (Bhattacharyya et al. 2008) & Cwa & 17.5 & 1520 & Temperate, dry winter, warm summer \\
M (Hati et al. 2007) & Cwa & 24.6 & $1277(1253)$ & Temperate, dry winter, hot summer \\
N (Hati et al. 2008) & Cwa & $23.7(23.1)$ & $1397(1450)$ & Temperate, dry winter, hot summer \\
O (Zhang et al. 2006) & Cwa & $14.5(13.0)$ & $619(550)$ & Temperate, dry winter, hot summer \\
P (Yang et al. 2011) & Cwa & $14.5(13.0)$ & $619(550)$ & Temperate, dry winter, hot summer \\
Q (Du et al. 2009) & Cfa & $17.6(17.2)$ & $1428(1354)$ & Temperate, no dry season, hot summer \\
A Qualiagro (own data) & Cfb & $10.4(11.0)$ & $641(643)$ & Temperate, no dry season, warm summer \\
B (Eden et al. 2011) & Cfb & $7.5(7.3)$ & $730(626)$ & Temperate, no dry season, warm summer \\
C (Eden et al. 2012b) & Cfb & $8.9(8.7)$ & $498(484)$ & Temperate, no dry season, warm summer \\
D (Leroy et al. 2008) & Cfb & 10.2 & 754 & Temperate, no dry season, warm summer \\
E (Arthur et al. 2011) & Cfb & $10.2(10.0)$ & $754(800)$ & Temperate, no dry season, warm summer \\
F (Carter 2007) & Dfb & 5.8 & 1129 & Cold, no dry season, warm summer \\
G (Miller et al. 2014) & Dfb & 5.4 & 392 & Cold, no dry season, warm summer \\
\end{tabular}

Where the exact location could not be found with the web tool, nearby towns were taken instead. Where rainfall and temperature were provided, they are listed in brackets next to the values from the web tool

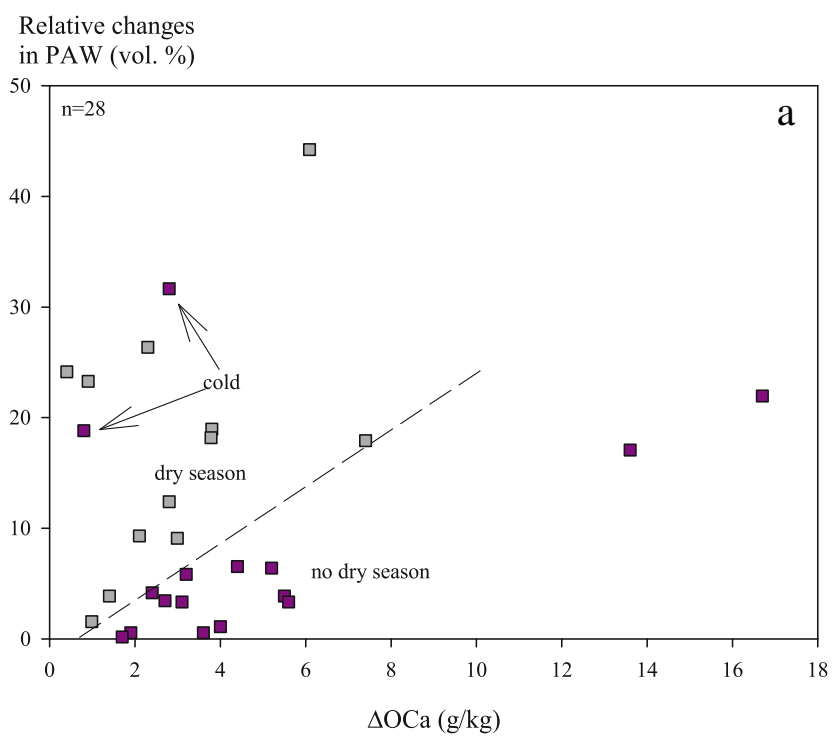

Fig. 10 Relative percent changes in PAW for soils from areas (a) with (grey) or without (purple) dry season as function of absolute change in soil OC (data from study $\mathrm{F}$ with cold climate presenting an exception is highlighted with arrows) and (b) relative percent changes in PAW as function of relative change in soil OC differentiating soils with OC content in the control treatment above (purple) or below (grey) $10 \mathrm{~g} / \mathrm{kg}$

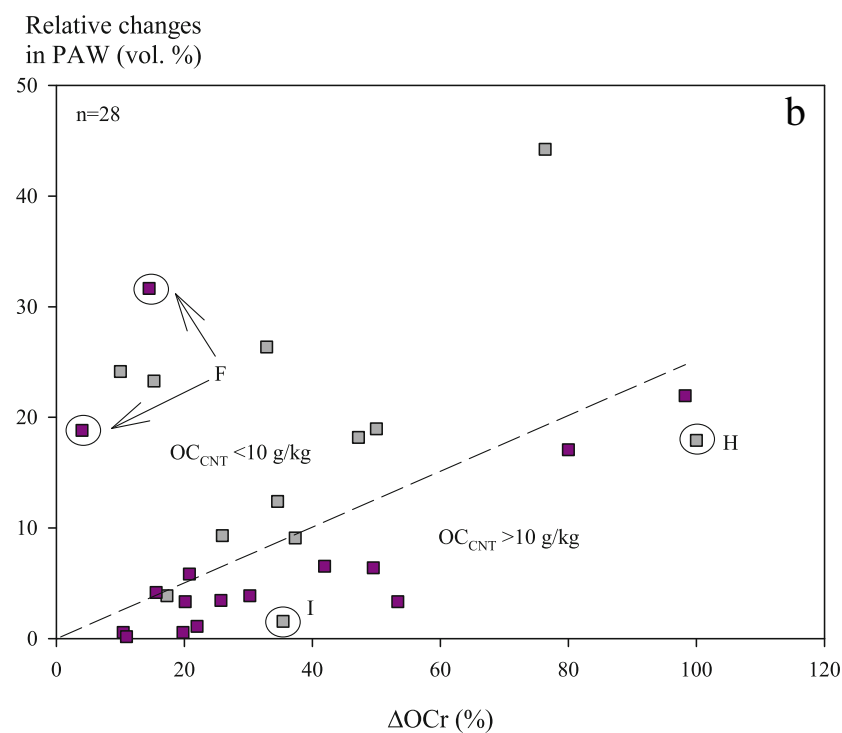

(the exceptions $F, H$, and $I$ are circled). The respective different groups in each

(a, b) are separated by dashed lines. Data from two studies are excluded (Du et al. 2009; Leroy et al. 2008) (PAW plant available water, $\triangle O C a$ absolute change in organic carbon, $\triangle \mathrm{OCr}$ relative change in organic carbon, $O C_{C N T}$ organic carbon control treatment) 


\section{Summary and conclusions}

Numerous independent studies confirmed a positive influence of organic waste application on water holding capacity; but also the opposite was reported. This review demonstrated that across continents, climate zones and soil types, PAW and consequently available water holding capacity (in $\mathrm{mm}$ ) in the topsoil are generally improved following organic waste application from various sources. In all experiments, PAW increases were observed, and in 15 of these experiments, this was the case in all amended treatments. In two experiments, reductions in PAW for some of the treatments were found.

Addition of organic material to soil is expected to manifest itself with increases in OC content in the incorporation layer. However, we found no significant relationship between absolute change in soil $\mathrm{OC}$ and total exogenous OC application via organic amendments, when considering results from all field long-term experiments at four continents in the analysis (Fig. 4a). Using the indicator of residual $\mathrm{OC}$, which provides information regarding the quality of organic material contained in organic waste, a significant relationship between the amount of residual OC from the amendments and relative OC percent change could be established. The results suggest that the applied amount of residual OC was better suited than the total amount of OC applied to explain the changes in soil OC.

PAW is more sensibly reported on a volumetric basis to allow for relatively simple conversion to depth of water; therefore, studies should always determine the soil bulk density along with the soil water retention. This is especially relevant in an agronomic context as well as when looking at water scarcity and irrigation needs. Moreover, when working with plants' water needs, it is important to take into account that plants also use water from deeper subsoil horizons. The effects of organic waste applications on the soil OC and PAW are largely limited to the topsoil, where amendments are incorporated and which hence is affected by cultivation (Wiesmeier et al. 2012). At the same time, a portion of the OM applied with amendments is likely to enter the subsoil, by different means (e.g. root channels, burrows). Regarding the influence of water-soluble OC percolating into the subsoil, Hobley et al. (2016) pointed out the importance of land use impacts on soil physical properties. Changing bulk density in cropped soils triggers changes in the pore system and may thus affect e.g. percolation. Ideally, when determining PAW, the entire soil profile containing plant roots should be considered. Being just a fraction of the total (topsoil and subsoil) PAW, topsoil PAW is nevertheless extremely important e.g. for the establishment and the initial growth period, among others.

Another issue is that PAW strongly depends on the choice of the matric potential for the water content at FC. This was demonstrated for data from those experiments that stated water contents at two of the suggested matric potentials. Therefore, in an agronomic context, it may be beneficial to determine the water content of FC in the field, in order to minimize deviations and to derive a more realistic value of the PAW. The results from the different field experiments may be better compared when using the relative changes in FC or PAW.

Across all experiments, relative percent changes in PAW on a volumetric basis are weakly, significantly affected by relative percent changes in $\mathrm{OC}$; however, relative percent changes in FC or WP were found to be not related with the relative percent changes in OC. While the two soil water retention values (i.e. FC and WP) were hence not significantly affected by the organic waste applications, PAW as the difference between the water contents at WP and FC was indirectly related to those applications. So, FC and WP are changing with application of OC such that the difference (PAW) is still related, but the amounts are not statistically significant. Using more data sets might affect this analysis.

Regarding the prediction of FC and WP, and thus PAW, two sets of PTFs were tested on the experiments that reported textural information. The PTFs by Rawls et al. (2003) are fairly well suited to predict FC and WP; for PAW, they performed even better. Fifty-two of 66 water contents and six of 11 soils were well predicted lying within the range of error indicated. However, the reductions in PAW encountered in one of the experiments could not be described by any of the PTFs, which was though expected. Nonetheless, the data here confirmed the conclusion of Rawls et al. (2003) that water retention at FC is more strongly affected by OC content than that at WP, which means that PAW increases. This appears to contradict the previous conclusion, as FC and WP are obviously related to OC here, but Rawls et al. (2003) for one used a much larger data set (12.000 samples) and moreover found increases in PAW, which were explained by larger increases at FC than at WP.

Using the observations by Khaleel et al. (1981), the data in this review show a trend that in coarser-textured soils, increases in OC may increase water holding capacity at FC and WP more than in finer-textured soils. Also, most finertextured soils display larger increases in water holding capacity at FC, but not all. The PTFs provided by Khaleel et al. (1981) provide less accurate predictions than those by Rawls et al. (2003) even though they are based on OC increases from organic waste additions. This may be due to e.g. the smaller database and the textural classes' varying grain sizes used in the creation of the PTFs by Khaleel et al. (1981). It may also be rooted in the fact that only the sand fraction is included, while Rawls et al. (2003) also included clay. Disregarding the clay fraction means not to take into account the amount of mineral particles that have the largest surface area. Therefore, the PTFs by Rawls et al. (2003) must be expected to perform better and should be preferred. On PAW, no impact 
of texture in terms of coarser or finer could be discerned. While texture can be used to get an idea how small changes in OC might affect water holding capacity or whether increases in water content are larger at WP or FC, it apparently cannot be used to predict the changes in PAW in such a generalized way. This seemingly contradicts the findings by Rawls et al. (2003), but the differentiation here into coarser and finer may just be too broad compared to their precise inclusion of textural composition. Moreover, their larger data set may again play an important role in this context.

Dividing the experiments according to their prevailing climate revealed differences, which may either be ascribed to presence or absence of dry seasons or they may be due to different initial OC contents (as these data were often missing, the OC contents of controls were used, assuming that these treatments preserved a similar OC content). Both aspects may also be linked as the climatic conditions may affect the OC content. Studies conducted in regions with dry seasons and lower OC content in the control $(<10 \mathrm{~g} / \mathrm{kg})$ showed larger increases in PAW in regard to the increase in OC than studies from regions without dry seasons.

It would be of great interest to obtain more specific information regarding e.g. a specific region or climatic zone (beyond the division regarding the presence of dry seasons); however, more and additional data sets (experiments) are needed for such an analysis. This review contains 36 amended treatments, which satisfies the 30-sample rule of thumb for statistical analysis, while a subset e.g. for a specific region would not. A number of 36 treatments are also more than the amount of amended treatments stating PAW reported by Khaleel et al. (1981), which were 28 in total but only 12 from long-term experiments (14-85 years duration). In order to increase data availability, also, older publications or experiments with a shorter duration could be included.

Across all investigated aspects, organic waste amendments have shown to generally improve the investigated soils' FC and WP and increase OC and PAW in the incorporation layer. It follows that soils provided an improved basis for plant production without increasing irrigation or land used for agriculture. While texture also plays an important role, it shows that the type of organic amendment is crucial, as it alters PAW also in otherwise identical soils within the same experiment (cf. Table 1, map ID A, C, D, E, G, J, K, Q). This raises the issue of the quality of OM applied through the amendments. In this review, also, due to the limited data availability in the studies investigated, this aspect was not addressed in depth. However, it presents an important topic and it would be of interest to further investigate it. While the impacts of organic waste amendments on topsoil physical properties have been investigated e.g. in the reviewed studies, their influence on subsoil properties has received less attention and could be of particular interest in long-term experiments, where differences may have slowly evolved over time. Also, the observation of a possible effect of the initial OC content on structure formation related to PAW should be investigated; no study on this was found. Already at this point though, it can be stated that organic wastes recycled in agriculture are in fact beneficial for PAW.

Acknowledgements This work was granted by ADEME (French Environment and Energy Management Agency) within the PRO-Extern (Analyse des coûts et des bénéfices externes associés à la valorisation agricole des Produits Résiduaires Organiques) project. The Qualiagro experiment is conducted within a collaboration between INRA (French National Institute for Agricultural Research) and VEOLIA Environment, Research and Innovation. We thank L. Paetsch and T. Keller for providing us measurement data for the Qualiagro experiment. We would also like to thank the anonymous reviewers for their constructive comments, which helped us to improve our manuscript.

\section{References}

Abiven S, Menasseri S, Chenu C (2009) The effects of organic inputs over time on soil aggregate stability - a literature analysis. Soil Biol Biochem 41(1):1-12. doi:10.1016/j.soilbio.2008.09.015

Adewopo JB, VanZomeren C, Bhomia RK, Almaraz M, Bacon AR, Eggleston E, Judy JD, Lewis RW, Lusk M, Miller B, Moorberg C, Snyder EH, Tiedeman M (2014) Top-ranked priority research questions for soil science in the 21 century. Soil Sci Soc Am J 78(2):337347. doi:10.2136/sssaj2013.07.0291

Ajayi AE, Holthusen D, Horn R (2016) Changes in microstructural behaviour and hydraulic functions of biochar amended soils. Soil Tillage Res 155:166-175. doi:10.1016/j.still.2015.08.007

Al Majou H, Bruand A, Duval O (2008) The use of in situ volumetric water content at field capacity to improve the prediction of soil water retention properties. Can J Soil Sci 88(4):533-541. doi:10.4141/CJSS07065

Amundson R, Berhe AA, Hopmans JW, Olson C, Sztein AE, Sparks DL (2015) Soil and human security in the 21 st century. Science 348(6235):647-653. doi:10.1126/science.1261071

Anderson SH, Gantzer CJ, Brown JR (1990) Soil physical properties after 100 years of continuous cultivation. J Soil Water Conserv 45(1): $117-121$

Annabi M, Le Bissonnais Y, Le Villio-Poitrenaud M, Houot S (2011) Improvement of soil aggregate stability by repeated applications of organic amendments to a cultivated silty loam soil. Agric Ecosyst Environ 144(1):382-389. doi:10.1016/j.agee.2011.07.00

Arthur E, Cornelis WM, Vermang J, De Rocker E (2011) Amending a loamy sand with three compost types: impact on soil quality. Soil Use Manage 27(1):116-123. doi:10.1111/j.1475-2743.2010.00319.x

Bachmann J, Marmur A, Deurer M (2006) Soil hydrophobicity. In: Lal R (ed) Encyclopedia of soil science. Taylor \& Francis, p 1626-1629. doi:10.1081/E-ESS-120025111

Bandyopadhyay PK, Saha S, Mallick S (2011) Comparison of soil physical properties between a permanent fallow and a long-term ricewheat cropping with inorganic and organic inputs in the humid subtropics of eastern India. Commun Soil Sci Plan 42(4):435-449. doi: $10.1080 / 00103624.2011 .542358$

Bastida F, Moreno JL, Garcia C, Hernandez T (2007) Addition of urban waste to semiarid degraded soil: long-term effect. Pedosphere 17(5): 557-567. doi:10.1016/s1002-0160(07)60066-6

Baveye PC (2015) Grand challenges in the research on soil processes. Front Environ Sci 3:1-5. doi:10.3389/fenvs.2015.00010

Bhattacharyya R, Kundu S, Prakash V, Gupta HS (2008) Sustainability under combined application of mineral and organic fertilizers in a 
rainfed soybean-wheat system of the Indian Himalayas. Eur J Agron 28(1):33-46. doi:10.1016/j.eja.2007.04.006

Blanco-Canqui H, Hergert GW, Nielsen RA (2015) Cattle manure application reduces soil compactibility and increases water retention after 71 years. Soil Sci Soc Am J 79(1):212-223. doi:10.2136/sssaj2014.06.0252

Bouma J, Kwakernaak C, Bonfante A, Stoorvogel JJ, Dekker LW (2015) Soil science input in transdisciplinary projects in the Netherlands and Italy. Geoderma Regional 5:96-105. doi:10.1016/j.geodrs.2015.04.002

Brady NC, Weil RR (2008) The nature and properties of soils. The nature and properties of soils, vol, Ed. 14 edn. Prentice-Hall Inc., Upper Saddle River

Briggs LJ, McLane JW (1907) The moisture equivalent of soils. USDA Bur Soil Bul 45:1-23

Bruand A, Duval O, Gaillard H, Dartouth R, Jamange M (1996) Variability of the water retention properties of soils: importance of bulk density. Étude et gestion des Sols 3(1):27-40

Bueno JRP, Berton RS, da Siveira APD, Chiba MK, de Andrade CA, De Maria IC (2011) Chemical and microbiological attributes of an oxisol treated with successive applications of sewage sludge. Rev Bras Cienc Solo 35(4):1461-1470

Carter MR (2007) Long-term influence of compost on available water capacity of a fine sandy loam in a potato rotation. Can J Soil Sci 87(5):535-539. doi:10.4141/CJSS06042

Cass A, McGrath MC (2005) Compost benefits and quality for viticultural soils. Proceedings of the soil environment and vine mineral nutrition symposium, San Diego, California, USA, 29-30 June, 2004. American Society for Enology and Viticulture

Chakraborty D, Garg RN, Tomar RK, Dwivedi BS, Aggarwal P, Singh R, Behera UK, Thangasamy A, Singh D (2010) Soil physical quality as influenced by long-term application of fertilizers and manure under maize-wheat system. Soil Sci 175(3):128-136. doi:10.1097/SS. 0b013e3181d53bd7

Climate-Data http://en.climate-data.org/. Accessed 11.05.2016

Cogger CG (2005) Potential compost benefits for restoration of soils disturbed by urban development. Compost Sci Util 13(4):243251. doi:10.1080/1065657X.2005.10702248

Dane JH, Hopmans IW (2002) Water retention and storage: laboratory. In: Dane JH, Topp GC (eds) Methods of soil analysis. Part 4 - physical methods. Soil Science Society of America, Madison, pp 675-720

Diacono M, Montemurro F (2010) Long-term effects of organic amendments on soil fertility. A review. Agron Sustain Dev 30(2):401-422. doi:10.1051/agro/2009040

Du Z, Liu S, Xiao X, Yang G, Ren T (2009) Soil physical quality as influenced by long-term fertilizer management under an intensive cropping system. Int J Agric Bio Eng 2(1):19-27. doi:10.3965/j. issn.1934-6344.2009.01.019-027

Eden M, Schjonning P, Moldrup P, De Jonge LW (2011) Compaction and rotovation effects on soil pore characteristics of a loamy sand soil with contrasting organic matter content. Soil Use Manage 27(3): 340-349. doi:10.1111/j.1475-2743.2011.00344.x

Eden M, Moldrup P, Schjønning P, Scow KM, de Jonge LW (2012a) Soilgas phase transport and structure parameters for a soil under different management regimes and at two moisture levels. Soil Sci 177(9): 527-534. doi:10.1097/SS.0b013e318267ec85

Eden M, Moldrup P, Schjonning P, Vogel HJ, Scow KM, de Jonge LW (2012b) Linking soil physical parameters along a density gradient in a loess-soil long-term experiment. Soil Sci 177(1):1-11. doi:10. 1097/SS.0b013e31823745a9

Foley BJ, Cooperband LR (2002) Paper mill residuals and compost effects on soil carbon and physical properties. J Environ Qual 31(6): 2086-2095. doi:10.2134/jeq2002.2086

Gupta SC, Dowdy RH, Larson WE (1977) Hydraulic and thermal properties of a sandy soil as influenced by incorporation of sewage sludge. Soil Sci Soc Am J 41(3):601-605. doi:10.2136/sssaj1977. 03615995004100030035x
Haghiri F, Miller RH, Logan TJ (1978) Crop response and quality of soil leachate as affected by land application of beef-cattle waste. J Environ Qual 7(3):406-412. doi:10.2134/jeq1978.00472425000700030023x

Hati KA, Swarup A, Dwivedi AK, Misra AK, Bandyopadhyay KK (2007) Changes in soil physical properties and organic carbon status at the topsoil horizon of a vertisol of central India after 28 years of continuous cropping, fertilization and manuring. Agric Ecosyst Environ 119(1-2):127-134. doi:10.1016/j.agee.2006.06.017

Hati KM, Swarup A, Mishra B, Manna MC, Waniari RH, Mandal KG, Misra AK (2008) Impact of long-term application of fertilizer, manure and lime under intensive cropping on physical properties and organic carbon content of an Alfisol. Geoderma 148(2):173-179. doi:10.1016/j.geoderma.2008.09.015

Haynes RJ, Naidu R (1998) Influence of lime, fertilizer and manure applications on soil organic matter content and soil physical conditions: a review. Nutr Cycl Agroecosyst 51(2):123-137. doi:10.1023/ a: 1009738307837

Herencia JF, Garcia-Galavis PA, Maqueda C (2011) Long-term effect of organic and mineral fertilization on soil physical properties under greenhouse and outdoor management practices. Pedosphere 21(4): 443-453. doi:10.1016/S1002-0160(11)60146-X

Hobley E, Baldock J, Hua Q, Wilson B (2016) Land-use contrasts reveal instability of subsoil organic carbon. Glob Change Biol n/a-n/a. doi: 10.1111/gcb.13379

Hudson BD (1994) Soil organic-matter and available water capacity. J Soil Water Conserv 49(2):189-194

Huntington TG (2006) Available water capacity and soil organic matter. In: Encyclopedia of soil science. Taylor and Francis, New York, pp 139-143. doi:10.1081/E-ESS-120018496

IPCC (2007) Climate change 2007: impacts, adaptation and vulnerability. Fourth Assessment Report of the Intergovernmental Panel on Climate Change. Cambridge University, Cambridge

Johnston AE (1986) Soil organic matter, effects on soils and crops. Soil Use Manage 2(3):97-105. doi:10.1111/j.1475-2743.1986.tb00690.x

Kaiser M, Ellerbrock RH, Gerke HH (2007) Long-term effects of crop rotation and fertilization on soil organic matter composition. Eur J Soil Sci 58(6):1460-1470. doi:10.1111/j.1365-2389.2007.00950.x

Katterer T, Andren O, Jansson PE (2006) Pedotransfer functions for estimating plant available water and bulk density in Swedish agricultural soils. Acta Agric Scand Sect B-Soil Plant Sci 56(4):263-276. doi:10.1080/09064710500310170

Kay BD (1997) Soil structure and organic carbon: a review. In: Lal R, Kimble JM, Follett RF, Stewart BA (eds) Soil processes and the carbon cycle. CRC, Boca Raton

Khaleel R, Reddy KR, Overcash MR (1981) Changes in soil physicalproperties due to organic waste applications - review. J Environ Qual 10(2):133-141

Klute A, Jacob WC (1950) Physical properties of Sassafras silt loam as affected by long-time organic matter additions. Soil Sci Soc Amer Proc 14:24-28

Köppen W (1918) Klassifikation der Klimate nach Temperatur, Niederschlag und Jahresablauf (Classification of climates according to temperature, precipitation and seasonal cycle). Petermanns Geogr Mitt 64:193-203

Körschens M (2006) The importance of long-term field experiments for soil science and environmental research $-\mathrm{a}$ review. Plant Soil Environ 52(Special Issue): 1-8

Lashermes G, Nicolardot B, Parnaudeau V, Thuriès L, Chaussod R, Guillotin ML, Linères M, Mary B, Metzger L, Morvan T, Tricaud A, Villette C, Houot S (2009) Indicator of potential residual carbon in soils after exogenous organic matter application. Eur J Soil Sci 60(2):297-310. doi:10.1111/j.1365-2389.2008.01110.x

Leroy BLM, Herath H, De Neve S, Gabriels D, Bommele L, Reheul D, Moens M (2008) Effect of vegetable, fruit and garden (VFG) waste compost on soil physical properties. Compost Sci Util 16(1):43-51. doi:10.1080/1065657X.2008.10702354 
Lin H (2014) A new worldview of soils. Soil Sci Soc Am J 78(6):18311844. doi:10.2136/sssaj2014.04.0162

Liyanage TDP, Leelamanie DAL (2016) Influence of organic manure amendments on water repellency, water entry value, and water retention of soil samples from a tropical Ultisol. J Hydrol Hydromech 64(2):160-166. doi:10.1515/johh-2016-0025

Mamo H, Moncrief JF, Rosen CJ, Halbach TR (2000) The effect of municipal solid waste compost application on soil water and water stress in irrigated corn. Compost Sci Util 8(3):236-246. doi:10. 1080/1065657X.2000.10701996

Marshall TJ (1959) Relations between water and soil. vol 50. Farnham Royal Bucks

Miller JJ, Beasley BW, Drury CF, Larney FJ, Hao X (2014) Influence of long-term ( $9 \mathrm{yr}$ ) composted and stockpiled feedlot manure application on selected soil physical properties of a clay loam soil in Southern Alberta. Compost Sci Util 23(1):1-10. doi:10.1080/ 1065657x.2014.963741

Minasny B, McBratney AB (2003) Integral energy as a measure of soilwater availability. Plant Soil 255(2):653-662. doi:10.1023/A: 1022825732324

Monaco E, Bonfante A, Alfieri SM, Basile A, Menenti M, De Lorenzi F (2014) Climate change, effective water use for irrigation and adaptability of maize: a case study in southern Italy. Biosyst Eng 128:8299. doi:10.1016/j.biosystemseng.2014.09.001

Monnier G (1965) Action des matières organiques sur la stabilité structurale des sols. Dissertation, Paris

Obriot F, Stauffer M, Goubard Y, Cheviron N, Peres G, Eden M, Revallier A, Vieublé-Gonod L, Houot S (2016) Multi-criteria indices to evaluate the effects of repeated organic amendment applications on soil and crop quality. Agric Ecosyst Environ 232:165-178. doi:10.1016/ j.agee.2016.08.004

Ojeda G, Mattana S, Avila A, Alcaniz JM, Volkmann M, Bachmann J (2015) Are soil-water functions affected by biochar application? Geoderma 249:1-11. doi:10.1016/j.geoderma.2015.02.014

Olness A, Archer D (2005) Effect of organic carbon on available water in soil. Soil Sci 170(2):90-101. doi:10.1097/01.ss.0000155496.63323.35

Ouattara K, Ouattara B, Assa A, Michel SP (2006) Long-term effect of ploughing, and organic matter input on soil moisture characteristics of a Ferric Lixisol in Burkina Faso. Soil Tillage Res 88(1/2):217224. doi:10.1016/j.still.2005.06.003

Ozenc DB, Ozenc N (2008) Short-term effects of hazelnut husk compost and organic amendment applications on clay loam soil. Compost Sci Util 16(3):192-199. doi:10.1080/1065657X.2008.10702377

Peltre C (2012) CARBO-PRO Carbon storage in soil following organic waste products application. http://www.carbo-pro.fr/\#

Peltre C, Christensen BT, Dragon S, Icard C, Katterer T, Houot S (2012) RothC simulation of carbon accumulation in soil after repeated application of widely different organic amendments. Soil Biol Biochem 52:49-60. doi:10.1016/j.soilbio.2012.03.023

Pollacco JAP (2008) A generally applicable pedotransfer function that estimates field capacity and permanent wilting point from soil texture and bulk density. Can J Soil Sci 88(5):761-774. doi:10.4141/CJSS07120

Pribyl DW (2010) A critical review of the conventional SOC to SOM conversion factor. Geoderma 156(3-4):75-83. doi:10.1016/j. geoderma.2010.02.003

Rasool R, Kukal SS, Hira GS (2008) Soil organic carbon and physical properties as affected by long-term application of FYM and inorganic fertilizers in maize-wheat system. Soil Tillage Res 101(1-2): 31-36. doi:10.1016/j.still.2008.05.015

Rawls WJ (1983) Estimating soil bulk-density from particle-size analysis and organic-matter content. Soil Sci 135(2):123-125. doi:10.1097/ 00010694-198302000-00007
Rawls WJ, Pachepsky YA, Ritchie JC, Sobecki TM, Bloodworth H (2003) Effect of soil organic carbon on soil water retention. Geoderma 116(1-2):61-76. doi:10.1016/s0016-7061(03)00094-6

Riley H, Pommeresche R, Eltun R, Hansen S, Korsaeth A (2008) Soil structure, organic matter and earthworm activity in a comparison of cropping systems with contrasting tillage, rotations, fertilizer levels and manure use. Agric Ecosyst Environ 124(3-4):275-284. doi:10. 1016/j.agee.2007.11.002

Romano N, Santini S (2012) Available water. In: Dane JH, Topp GC (eds) Methods of soil analysis part 4 physical methods. Soil Sci Soc America, Madison, pp 731-734

Shukla MK, Lal R, Ebinger M (2004) Soil quality indicators for the North Appalachian Experimental Watersheds in Coshocton Ohio. Soil Sci 169(3):195-205. doi:10.1097/01.ss.0000122523.03492.79

da Silva AP, Kay BD, Perfect E (1994) Characterization of the least limiting water range of soils. Soil Sci Soc Am J 58(6):1775-1781. doi:10.2136/sssaj1994.03615995005800060028x

van Soest PJ (1963) Use of detergents in the analysis of fibrous feeds: II. A rapid method for the determination of fibre and lignin. J Assoc Off Anal Chem 46:829-835

van Soest PJ, Wine RH (1967) Use of detergents in the analysis of fibrous feeds. IV. Determination of plant cell-wall constituents. J Assoc Off Anal Chem 58:50-55

Sposito G (2013) Green water and global food security. Vadose Zone J 12(4). doi:10.2136/vzj2013.02.0041

Thomas MD, Harris K (1926) The moisture equivalent of soils. Soil Sci 21(6):411-424. doi:10.1097/00010694-192606000-00001

Tittarelli F, Petruzzelli G, Pezzarossa B, Civilini M, Benedetti A, Sequi P (2007) Quality and agronomic use of compost. In: Diaz MdBWB L.F., Stentiford E (eds) Waste management series, vol 8. Elsevier, p 119-157. doi:10.1016/S1478-7482(07)80010-8

UN (2014) Sustainable Development Goals https://sustainabledevelopment. un.org/focussdgs.html

Veihmeyer FJ, Hendrickson AH (1927) The relation of soil moisture to cultivation and plant growth. Proc and Papers First Internal Congress Soil Sci 3:498-513

Wiesmeier M, Spörlein P, Geuß U, Hangen E, Haug S, Reischl A, Schilling B, Lützow M, Kögel-Knabner I (2012) Soil organic carbon stocks in southeast Germany (Bavaria) as affected by land use, soil type and sampling depth. Glob Change Biol 18(7):2233-2245. doi: 10.1111/j.1365-2486.2012.02699.x

Williams RJB, Cooke GW (1961) Some effects of farmyard manure and grass residues on soil structure. Soil Sci 92(1):30-39. doi:10.1097/ 00010694-196107000-00005

Wosten JHM, Pachepsky YA, Rawls WJ (2001) Pedotransfer functions: bridging the gap between available basic soil data and missing soil hydraulic characteristics. J Hydrol 251(3-4):123-150. doi:10.1016/ s0022-1694(01)00464-4

Yang XY, Li PR, Zhang SL, Sun BH, Chen XP (2011) Long-termfertilization effects on soil organic carbon, physical properties, and wheat yield of a loess soil. J Plant Nutr Soil Sci 174(5):775-784. doi:10.1002/jpln.201000134

Zhang S, Yang X, Wiss M, Grip H, Lövdahl L (2006) Changes in physical properties of a loess soil in China following two long-term fertilization regimes. Geoderma 136(3-4):579-587. doi:10.1016/j. geoderma.2006.04.015

Zhao YC, Wang P, Li JL, Chen YR, Ying XZ, Liu SY (2009) The effects of two organic manures on soil properties and crop yields on a temperate calcareous soil under a wheat-maize cropping system. Eur J Agron 31(1):36-42. doi:10.1016/j.eja.2009.03.001 